Article

You have full text access to this content

\title{
Global analysis and indeterminacy in a two-sector growth model with human capital
}

1. Angelo Antoci ${ }^{1}$,

2. Marcello Galeotti ${ }^{2}$ and

3. Paolo Russu ${ }^{3}$

Article first published online: 10 NOV 2014

DOI: $10.1111 /$ ijet.12042

(C) IAET

Issue

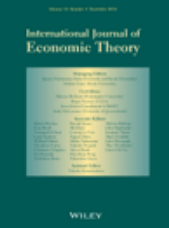

\section{International Journal of Economic Theory}

Volume 10, Issue 4, (/doi/10.1111/ijet.v10.4/issuetoc) pages 313-338, December 2014

(http $/ /$ www.altmetric.com/details.php?

domain $=$ onlinelibrary.wiley.com\&doi $=10.1111$ /ijet.12042)

Additional Information

How to Cite

Antoci, A., Galeotti, M. and Russu, P. (2014), Global analysis and indeterminacy in a two-sector growth model with human capital. International Journal of Economic Theory, 10: 313338. doi: $10.1111 /$ ijet. 12042

Author Information

1

DiSea \& CRENoS, University of Sassari, Sassari, Italy

2

DiSIA, University of Florence, Florence, Italy

3

DiSea \& CRENoS, University of Sassari, Sassari, Italy

Email: Angelo Antoci (angelo.antoci@virgilio.it)

The authors wish to express their thanks to the anonymous referee for his/her accurate and enlightening observations, which helped them to improve the paper. Moreover, they wish to thank Prof. Russell Allan Johnson for his precious comments on a preliminary version of the manuscript. Clearly the usual caveats apply. The research of Angelo Antoci and

Paolo Russu is financed by Regione Autonoma della Sardegna (L.R. 7/2007) under the project "Capitale sociale e divari economici regionali".

Publication History

1. Issue published online: 10 NOV 2014

2. Article first published online: 10 NOV 2014

- $\underline{\text { Abstract (/doi/10.1111/ijet.12042/abstract) }}$

- Article

- References (/doi/10.1111/ijet.12042/references)

- $\underline{\text { Cited By (/doi/10.1111/ijet.12042/citedby) }}$ 
2004\&rft_val_fint=info\%3Aofi $\% 2 \mathrm{Ffmt} \% 3 \mathrm{Akev} \% 3 \mathrm{Amtx} \% 3 \mathrm{Ajournal} \& \mathrm{rft.genre}=$ article\&rft.jtitle=International $\% 20 \mathrm{Journal} \% 20$ of $\% 20$ Economic\%20Theory\&rft.stitle=Int $\% 20 \mathrm{Jnl} \% 20$ 12-01\&rft.issn $=1742-7355 \&$ rft.eissn $=1742-7363 \&$ rff id=info $\% 3$ Asid $\% 2$ Fwiley.com\%3AOnlineLibrary)

\section{Keywords:}

global and local indeterminacy; endogenous growth; human capital; poverty trap; two-sector model
Abstract
1. Top of page
2. $\underline{\text { Abstract }}$
3. 1 Introduction
4. 2 The model
5. 3 A change of variables
6. 4 Global analysis in a two-dimensional context
7. 5 Global analysis in a three-dimensional context
8. 6 Concluding remarks
9. Appendix
10. $\underline{\text { References }}$

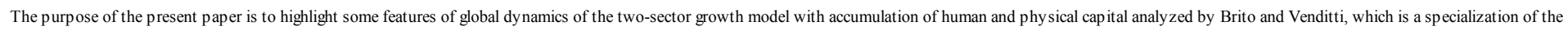
model proposed by Mulligan and Sala-i-Martín. In particular, our analy sis focuses on the context in which the Brito-Venditti system admits two balanced growth paths, each corresponding, after a change of variables, to an equilibrium point of a three-dimensional system, and proves the possible existence of points $\bar{P}$ such that in any neighborhood of $\bar{P}$ ly ing on the plane corresponding to fixed values of the state variables there exist points $\bar{Q}$

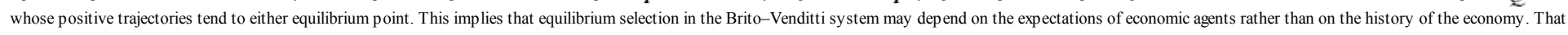
is, economies with identical technologies and preferences, starting from the same initial values of the state variables (history), may follow rather different equilibrium trajectories according to the economic agents' choices of the initial values of the jumping variables (expectations). Moreover, we prove that the basins of attraction (two or three-dimensional) of locally indeterminate equilibrium points may be very large, as they can extend up to the boundary of the system phase space.

\section{Introduction}

\section{Top of page}

2. Abstract

3. 1 Introduction

4. 2 The model

5. 3 A change of variables

6. 4 Global analysis in a two-dimensional context

7. 5 Global analysis in a three-dimensional context

8. 6 Concluding remarks

9. Appendix

10. References

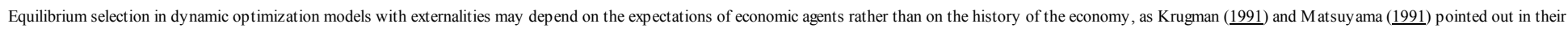

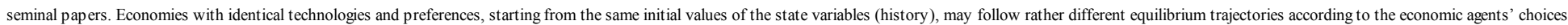

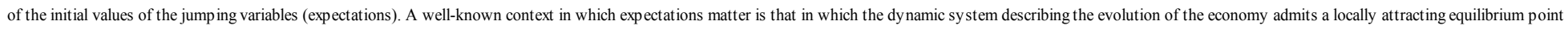

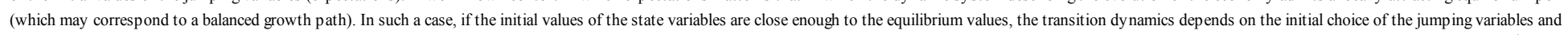

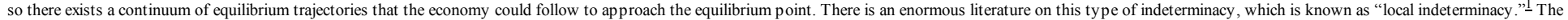

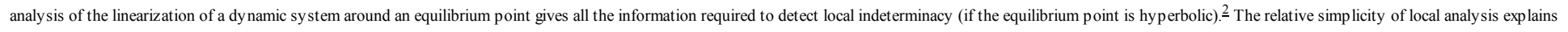
why many works in the literature focus on local indeterminacy issues. However, a fast-growing number of contributions suggest caution in drawing predictions on the future evolution of the economy based exclusively on local

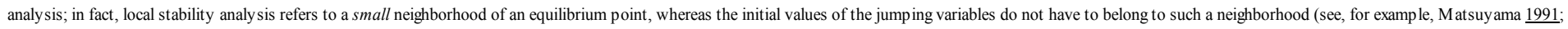

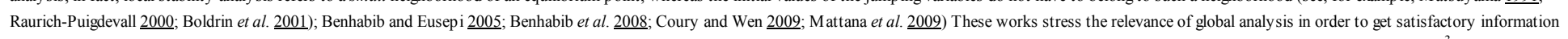

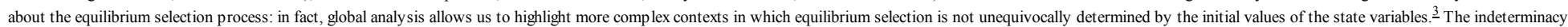

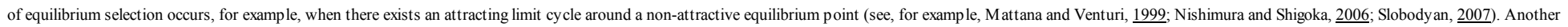

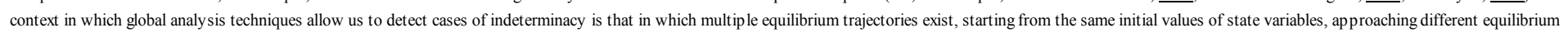

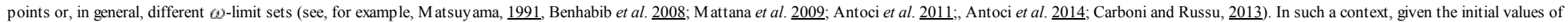
the state variables, the economy can follow equilibrium trajectories along which the long run behavior of the state variables is rather different, in that the trajectories converge to different $\omega$-limit sets. .4 all cases in which

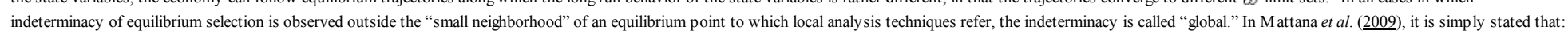
"If equilibrium is indeterminate for a reason different from the case of local indeterminacy, it is said that equilibrium is globally indeterminate."

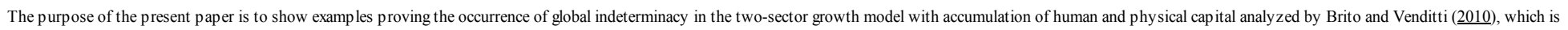

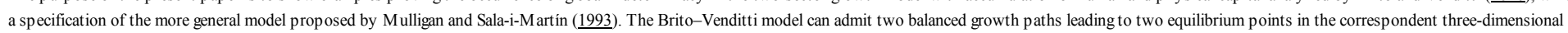

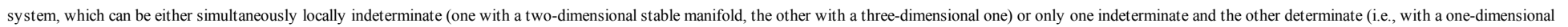

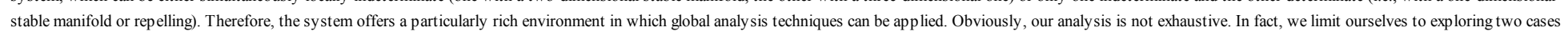
where the Brito-Venditti system admits two equilibrium points. In one, the two equilibrium points have, respectively, a two-dimensional and a one-dimensional stable manifold (i.e., they are, respectively, in the Brito-Venditti terminology, locally indeterminate of order 2 and determinate). In the other, the stable manifolds of the two equilibria have, respectively, dimension 2 and 3 (i.e., they are locally indeterminate of order 2 and 3 ). In both cases we

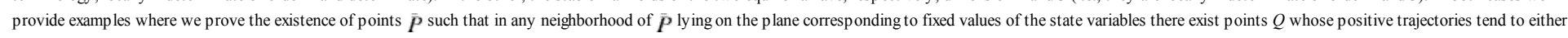

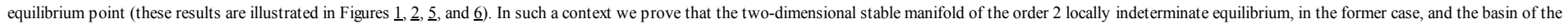
attracting equilibrium, in the latter case, are both unbounded (i.e., they extend to the boundary of the original phase space).

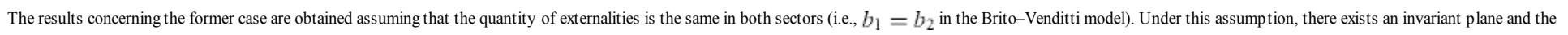

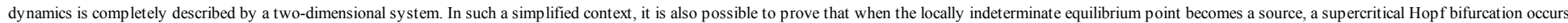

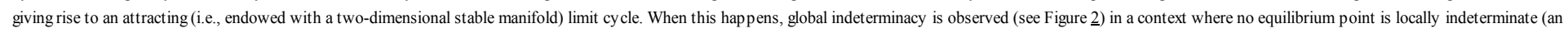




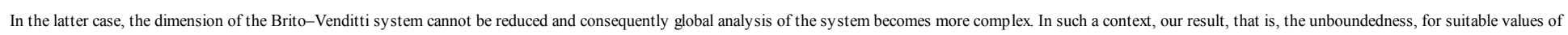

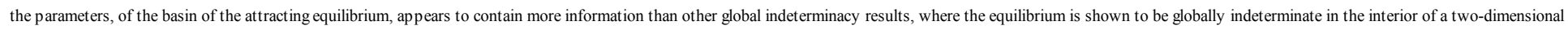
invariant region enclosed by a periodic or homoclinic orbit (see, for example, Benhabib et al., 2008; Mattana et al., 2009).

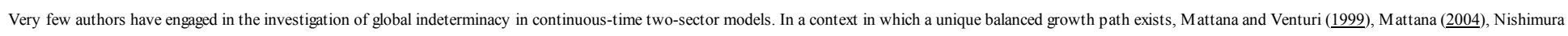

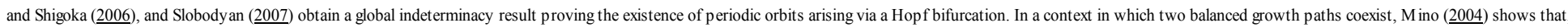

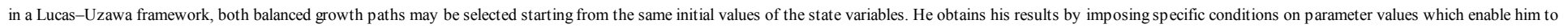

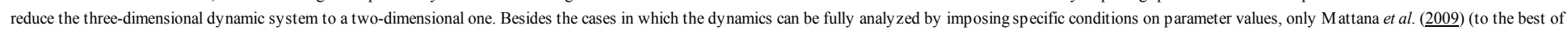

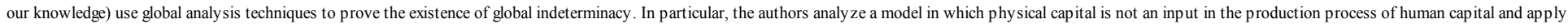

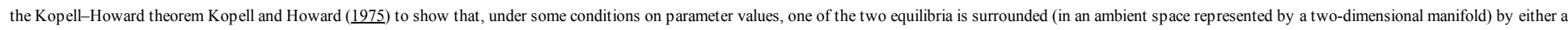
homoclinic orbit or a periodic orbit (or both).

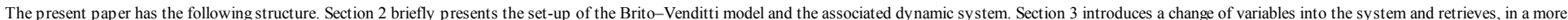

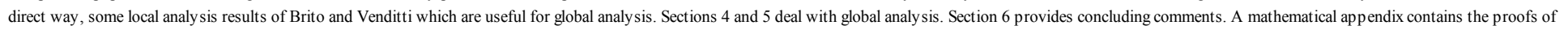
several of the results stated in the paper.

\section{The model}

\section{Top of page}

2. Abstract

3. 1 Introduction

4. 2 The model

5. 3 A change of variables

6. 4 Global analysis in a two-dimensional context

7. 5 Global analysis in a three-dimensional context

8. 6 Concluding remarks

\section{Appendix}

\section{References}

Brito and Venditti have analyzed a two-sector endogenous growth model in which the representative agent solves the following optimization problem:

$$
\max _{C(t), K_{11}(t), K_{21}(t), K_{12}(t), K_{22}(t)} \int_{0}^{+\infty} \frac{C(t)^{1-\sigma}-1}{1-\sigma} e^{-\rho t} d t
$$

subject to

$$
\begin{aligned}
\dot{K}_{1}(t) & =Y_{1}(t)-C(t), \\
\dot{K}_{2}(t) & =Y_{2}(t), \\
Y_{j}(t) & =e_{j}(t) K_{1 j}(t)^{\beta_{1 j}} K_{2 j}(t)^{\beta_{2 j}}, \quad j=1,2, \\
K_{i}(t) & =K_{i 1}(t)+K_{i 2}(t), \quad i=1,2, \\
K_{j}(0) & >0,\left\{e_{j}(t)\right\}_{t=0}^{+\infty}, \quad j=1,2, \quad \text { given, }
\end{aligned}
$$

where $K_{1}(t)$ and $K_{2}(t)$ represent physical and human capital, respectively; $K_{i j}(t)$ is the amount of capital good $i=1,2$ used in sector $j=1,2 ; \sigma>0$ is the inverse of the elasticity of intertemporal substitution in consumption; and $\rho>0$ is the discount rate.

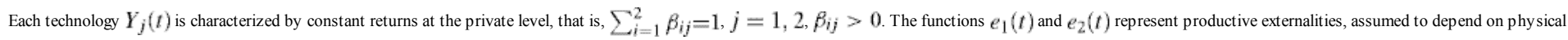
capital by unit of efficient labor, that is,

$$
e_{j}(t)=\bar{k}(t)^{b_{j}}, \quad j=1,2,
$$

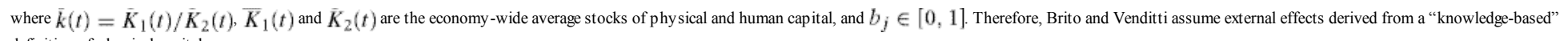
definition of physical capital.

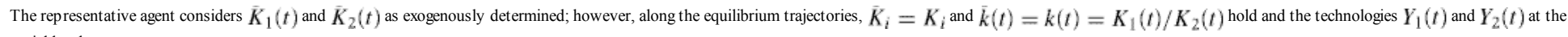
social level are

$$
\begin{aligned}
& Y_{1}(t)=K_{11}(t)^{\beta_{11}} K_{21}(t)^{\beta_{21}} k(t)^{b_{1}}=K_{11}(t)^{\beta_{11}} K_{21}(t)^{\beta_{21}}\left(\frac{K_{11}(t)+K_{12}(t)}{K_{21}(t)+K_{22}(t)}\right)^{b_{1}}, \\
& Y_{2}(t)=K_{12}(t)^{\beta_{12}} K_{22}(t)^{\beta_{22}} k(t)^{b_{2}}=K_{12}(t)^{\beta_{12}} K_{22}(t)^{\beta_{22}}\left(\frac{K_{11}(t)+K_{12}(t)}{K_{21}(t)+K_{22}(t)}\right)^{b_{2}} .
\end{aligned}
$$

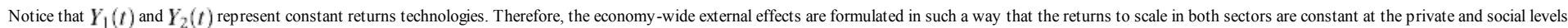

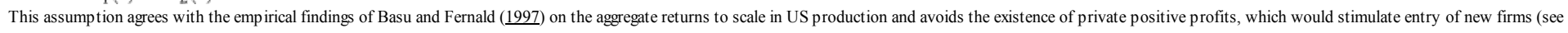
Benhabib and Nishimura, 1998, p. 69).

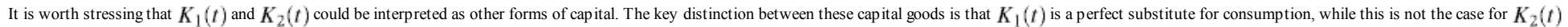

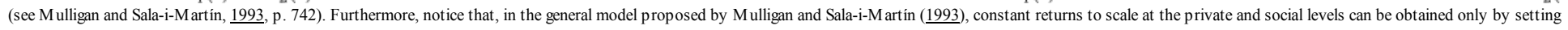

$$
e_{j}(t)=\left(\frac{\bar{K}_{1}(t)}{\bar{K}_{2}(t)}\right)^{b_{j}} \quad \text { or } \quad e_{j}(t)=\left(\frac{\bar{K}_{2}(t)}{\bar{K}_{1}(t)}\right)^{b_{j}} .
$$

That is, it is necessary to assume some type of "congestion effect" produced by one capital good on the other, as done by Brito and Venditti.

The Hamiltonian and Lagrangian in current value terms associated with problem (1) are respectively

$$
\begin{aligned}
& \mathcal{H}=\frac{C(t)^{1-\sigma}-1}{1-\sigma}+P_{1}\left(Y_{1}-C\right)+P_{2} Y_{2}, \\
& \mathcal{L}=\mathcal{H}+R_{1}\left(K_{1}-K_{11}-K_{12}\right)+R_{2}\left(K_{2}-K_{21}-K_{22}\right),
\end{aligned}
$$

where $P_{i}$ is the utility price and $R_{i}$ the rental rate of good $i=1,2$. 


$$
\begin{aligned}
k_{1}(t) & :=K_{1}(t) e^{-\gamma}, \\
k_{2}(t) & :=K_{2}(t) e^{-\gamma t}, \\
c(t) & =C(t) e^{-\gamma t}, \\
p_{1}(t): & =P_{1}(t) e^{-\gamma_{p} t}, \\
p_{2}(t) & =P_{2}(t) e^{-\gamma_{p} t},
\end{aligned}
$$

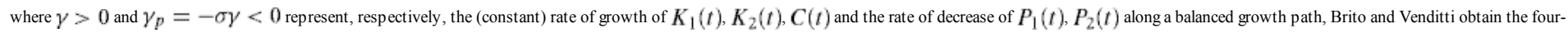
dimensional dynamic system given by

$$
\left\{\begin{array}{l}
\dot{p}_{1}=p_{1}\left(\rho+\sigma \gamma-r_{1}(\pi, k)\right) \\
\dot{p}_{2}=p_{2}\left(\rho+\sigma \gamma-r_{2}(\pi, k)\right) \\
\dot{k}_{1}=\left(\alpha_{11}(\pi, k)-\gamma\right) k_{1}+\alpha_{12}(\pi, k) k_{2}-p_{1}^{-1 / \sigma} \\
\dot{k}_{2}=\alpha_{21}(\pi, k) k_{1}+\alpha_{22}(\pi, k) k_{2}-\gamma k_{2}
\end{array}\right.
$$

where $k_{1}$ and $k_{2}$ are the state variables, while $p_{1}$ and $p_{2}$ are the jumping variables, with $\pi:=\frac{p_{2}}{p_{1}}=\frac{p_{2}}{P_{1}}$ and $k:=\frac{k_{1}}{k_{2}}=\frac{K_{1}}{K_{2}}$. The transversality conditions are

$$
\lim _{t \rightarrow+\infty} p_{1}(t) k_{1}(t) e^{[\gamma(1-\sigma)-\rho] t}=\lim _{t \rightarrow+\infty} p_{2}(t) k_{2}(t) e^{[\gamma(1-\sigma)-\rho] t}=0,
$$

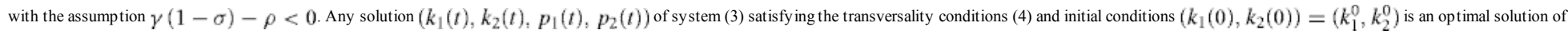
problem (1) in that problem (1) satisfies Arrow's condition.

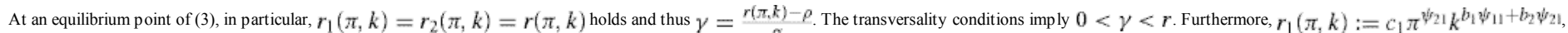
$r_{2}(\pi, k):=c_{2} \pi^{-\psi_{12}} k^{b_{1} \psi_{12}+b_{2} \psi_{22}}, \alpha_{i j}(\pi, k):=\psi_{i j} r_{j}(\pi, k) \pi^{j-i}, c_{i}:=\left(\beta_{i}^{*}\right)^{\psi_{i i}}\left(\beta_{j}^{*}\right)^{\psi_{j i}}, i \neq j, \beta_{i}^{*}:=\beta_{1 i}^{\beta_{1 i}} \beta_{2 i}^{\beta_{2 i}}, b_{1}, b_{2} \in[0,1] \cdot \frac{5}{\cdot}$ The coefficients $\psi_{i j}$ are the components of the matrix

$$
\Psi=\left(\begin{array}{ll}
\psi_{11} & \psi_{12} \\
\psi_{21} & \psi_{22}
\end{array}\right)=\frac{1}{\beta_{11}-\beta_{12}}\left(\begin{array}{cc}
\beta_{22} & -\beta_{12} \\
-\beta_{21} & \beta_{11}
\end{array}\right)=B^{-1}
$$

where

$$
B=\left(\begin{array}{ll}
\beta_{11} & \beta_{12} \\
\beta_{21} & \beta_{22}
\end{array}\right)
$$

is the matrix of private Cobb-Douglas coefficients satisfying $\beta_{11}+\beta_{21}=\beta_{12}+\beta_{22}=1, \beta_{11}-\beta_{12} \neq 0$. Consequently, the components of $\Psi$ satisfy the conditions $\psi_{11}+\psi_{21}=\psi_{12}+\psi_{22}=1$, $\psi_{11} \cdot \psi_{22}>0, \psi_{i i} \cdot \psi_{i j}<0$ for $i \neq j$. Furthermore, $\psi_{12}, \psi_{21}>0 \Longleftrightarrow \beta_{11}<\beta_{12}, \psi_{12}=\psi_{21} \Longleftrightarrow \beta_{12}=\beta_{21}$ and $\psi_{11}=\psi_{22} \Longleftrightarrow \beta_{11}=\beta_{22}$

\section{A change of variables}

\section{Top of page}

2. Abstract

3. 1 Introduction

4. 2 The model

5. 3 A change of variables

6. 4 Global analysis in a two-dimensional context

7. 5 Global analysis in a three-dimensional context

8. 6 Concluding remarks

9. Appendix

10. References

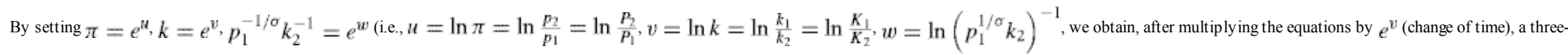
dimensional system defined in $\mathbb{R}^{3}$, whose trajectories generate those of (3). This system is given by

$$
\left\{\begin{aligned}
\dot{u}= & e^{v}\left(r_{1}(u, v)-r_{2}(u, v)\right)=f(u, v) \\
\dot{v}= & e^{v}\left(\psi_{11} r_{1}(u, v)-\psi_{22} r_{2}(u, v)+\psi_{12} r_{2}(u, v) e^{u-v}\right. \\
& \left.-\psi_{21} r_{1}(u, v) e^{v-u}\right)-e^{w}=g(u, v)-e^{w} \\
\dot{w}= & e^{v}\left(-\frac{\rho}{\sigma}+\frac{r_{1}(u, v)}{\sigma}-\psi_{22} r_{2}(u, v)-\psi_{21} r_{1}(u, v) e^{v-u}\right)=h(u, v)
\end{aligned}\right.
$$

where, in an abuse of notation, $r_{i}(u, v):=r_{i}\left(e^{u}, e^{v}\right)$.

An equilibrium point $(\bar{u}, \bar{v}, \bar{w})$ of system (5) corresponds to a one-dimensional manifold of equilibrium points of the Brito-Venditti system (3) defined, in the space $\left(\gamma, p_{1}, p_{2}, k_{1}, k_{2}\right)$, via the equations

$$
\begin{aligned}
\gamma & =\frac{r(\bar{u}, \bar{v})-\rho}{\sigma}, \\
p_{1} & =\left(e^{\bar{w}} k_{2}\right)^{-\sigma}, \\
p_{2} & =\bar{\pi} p_{1}=e^{\bar{u}} p_{1}=e^{\bar{u}}\left(e^{\bar{w}} k_{2}\right)^{-\sigma}, \\
k_{1} & =\bar{k} k_{2}=e^{\bar{v}} k_{2} .
\end{aligned}
$$

The local analysis results of Brito and Venditti can be retrieved by analyzing (5). In the rest of this section we focus on those our global analysis is built on.

Let

$$
\begin{aligned}
\tau & :=\frac{b_{1} \psi_{12}+b_{2} \psi_{21}}{\psi_{12}+\psi_{21}}, \\
\delta: & :=\frac{\left(b_{1}-b_{2}\right)\left(\psi_{12}+\psi_{21}-1\right)}{\psi_{12}+\psi_{21}},
\end{aligned}
$$


implying $0 \leq \tau \leq 1, \operatorname{sgn}(\delta)=\operatorname{sgn}\left(b_{1}-b_{2}\right)$. Since $\tau=0 \Longleftrightarrow b_{1}=b_{2}=0$, we assume in what follows that $\tau>0$.

It is easily computed that the possible equilibrium points of (5) lie on the plane $u=\delta v+\bar{d}$, with $\bar{d}:=\left(\psi_{12}+\psi_{21}\right)^{-1} \ln \frac{c_{2}}{c_{1}}$. Then

$$
r_{1}(\delta v+\bar{d}, v)=r_{2}(\delta v+\bar{d}, v)=r(v)=c e^{\tau v}, \quad c>0 .
$$

Moreover, two equilibrium points can exist only if the function $\widetilde{h}(v)=h(\delta v+\bar{d})$ has one (necessarily unique) relative extremum, which implies that the system parameters satisfy one of the following conditions:

1. $\psi_{12}, \psi_{21}>0$ (implying $\psi_{12}, \psi_{21}>1$ and therefore $|\delta|<1$ );

2. $\psi_{12}, \psi_{21}<0, \delta>1+\tau, \sigma^{-1}-\psi_{22}>0$;

3. $\psi_{12}, \psi_{21}<0,1<\delta<1+\tau, \sigma^{-1}-\psi_{22}<0$.

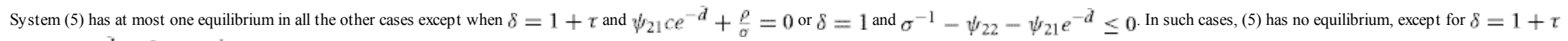
and $\psi_{21} c e^{-d}+\frac{\rho}{\sigma}=\sigma^{-1}-\psi_{22}=0$, when (5) has infinite equilibria.

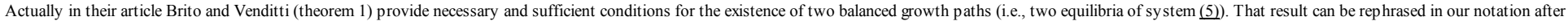
observing that, denoting by $\bar{v}$ and $v^{*}$ the values of $v$ where respectively $\widetilde{g}(v)=g(\delta v+\bar{d}, v)=0$ and $\widetilde{h}^{\prime}(v)=0$, the existence of two equilibria requires $v^{*}<\bar{v}$ and $\widetilde{h}(v) \widetilde{h}\left(v^{*}\right)<0$. Hence, after computing $\bar{v}=(1-\delta)^{-1}\left(\bar{d}+\ln \frac{\psi_{21}}{\psi_{12}}\right)$ and $v^{*}=(1-\delta)^{-1}\left(\bar{d}+\tau+\ln \frac{\sigma^{-1}-\psi_{22}}{\psi_{12(1+\tau-\delta)}}\right)$, we can state the following proposition:

Proposition 1. System (5) admits two equilibrium points if and only if one of the following three cases occurs:

1. $\psi_{12}, \psi_{21}>0$ (implying $\left.|\delta|<1\right), 0<\sigma^{-1}<1+\psi_{12} \frac{1-\delta}{\tau}, \max (0, r(\bar{v})(1-\sigma))<\rho<\frac{(1-\delta)\left(1-\psi_{22} \sigma\right)}{1+\tau-\delta} r\left(v^{*}\right)$;

2. $\psi_{12}, \psi_{21}<0, \delta>1+\tau, \sigma^{-1}>\max \left(\psi_{22}, 1-\psi_{12} \frac{\delta-1}{\tau}\right), \frac{(\delta-1)\left(1-\psi_{22} \sigma\right)}{\delta-1-\tau} r\left(v^{*}\right)<\rho<r(\bar{v})(1-\sigma)\left(\right.$ which requires $\left.\frac{r(\bar{v})}{r}\left(v^{*}\right)=e^{\tau\left(\bar{v}-v^{*}\right)}>\frac{(\delta-1)\left(1-\psi_{22} \sigma\right)}{(\delta-1-\tau)(1-\sigma)}\right)$;

3. $\psi_{12}, \psi_{21}<0,1<\delta<1+\tau, 0<\sigma^{-1}<\min \left(\psi_{22}, 1-\psi_{12} \frac{\delta-1}{\tau}\right), \max (0, r(\bar{v})(1-\sigma))<\rho<\frac{(\delta-1)\left(\psi_{22} \sigma-1\right)}{1+\tau-\delta} r\left(v^{*}\right)$.

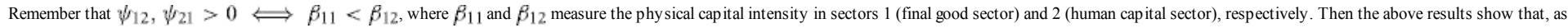

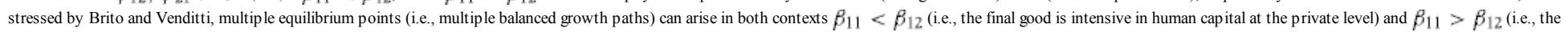
final good is intensive in physical capital at the private level). $\underline{6}$

Now let $P_{0}=\left(u_{0}, v_{0}, w_{0}\right)$ be an equilibrium point of (5) and set $r\left(v_{0}\right)=r_{0}$. Then its Jacobian matrix is

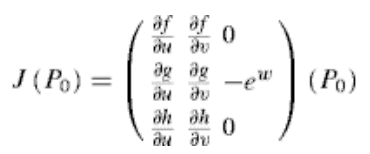

where $\frac{\partial f}{\partial u}=e^{v_{0}} r_{0}\left(\psi_{12}+\psi_{21}\right), \frac{\partial f}{\partial v}=-\delta e^{v_{0}} r_{0}\left(\psi_{12}+\psi_{21}\right)$, while $\frac{\partial g}{\partial u}<0$. Then set $\tilde{h}(v):=h(\delta v+\bar{d}, v)$. It easily follows that

$$
\operatorname{sgn}\left[\operatorname{det} J\left(P_{0}\right)\right]=\operatorname{sgn}\left[\tilde{h}^{\prime}\left(v_{0}\right)\left(\psi_{12}+\psi_{21}\right)\right] .
$$

In particular, assume that $\psi_{12}, \psi_{21}>0$ and two equilibria exist, $P_{1}=\left(u_{1}, v_{1}, w_{1}\right)$ and $P_{2}=\left(u_{2}, v_{2}, w_{2}\right)$, with $v_{1}<v_{2}$. Then $\operatorname{det} J\left(P_{1}\right)>0>\operatorname{det} J\left(P_{2}\right)$.

On the other hand, suppose that $\psi_{12}, \psi_{21}<0$ and $\delta \leq 1$. In this case at most one equilibrium $P_{0}$ exists, where $\operatorname{det} J\left(P_{0}\right)<0$.

The following proposition rephrases one of Brito and Venditti's results:

Proposition 2. Let $P$ be one of the equilibria of (5). Then $\delta \geq 0$ (i.e., $b_{1} \geq b_{2}$ ) implies trace $[J(P)]>0$.

Proof I. See the Appendix. $\square$

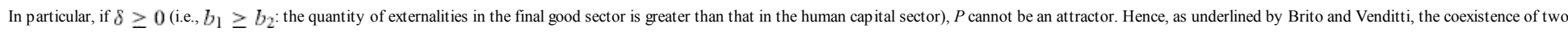

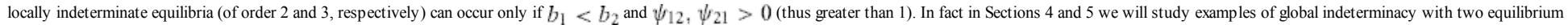
points in the context of Case 1 of Proposition 1 (i.e., when, in particular, $\psi_{12}, \psi_{21}>0$ ). As to Cases 2 and 3, we reformulate results stated in theorem 5 Brito and Venditti (2010), illustrating the local stability of the two equilibria, in the following proposition:

Proposition 3. Assume Cases 2 or 3 of Proposition 1 hold and denote the two equilibria by $P_{1}=\left(u_{1}, v_{1}, w_{1}\right)$ and $P_{2}=\left(u_{2}, v_{2}, w_{2}\right)$, with $v_{1}<v_{2}$. Then, in Case $2, P_{1}$ is a source while $P_{2}$ is a saddle with a onedimensional stable manifold. In Case $3, P_{1}$ is a saddle with a one-dimensional stable manifold while $P_{2}$ can be either repelling or locally indeterminate of order 2 (i.e., its stable manifold is two-dimensional).

Proof 2. See the Appendix. $\square$

Example 1. In system (5), let $c_{1}=c_{2}=1$ (this can always be obtained by a suitable translation of $(u, v, w)$ and a rescaling of the parameter $\rho$ and the time variable $t$ ). Set $\psi_{21}=-\varepsilon-\varepsilon^{3}, \psi_{12}=-\varepsilon^{2}$, $\sigma^{-1}=1-\varepsilon^{2}, \rho=2 \exp \left(\tau v_{2}\right) \sigma \varepsilon^{4}, b_{1}=1, b_{1}-b_{2}=\varepsilon(1+\varepsilon)\left(1+\varepsilon+\varepsilon^{2}\right) /\left(1+\varepsilon+\varepsilon^{2}+\varepsilon^{3}\right)$, where $\varepsilon>0$ is sufficiently small. Then the conditions of Case 3 are satisfied and there exist two

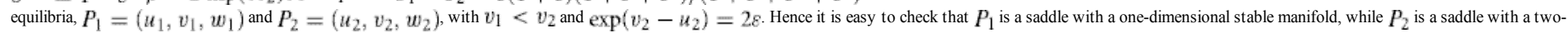
dimensional stable manifold.

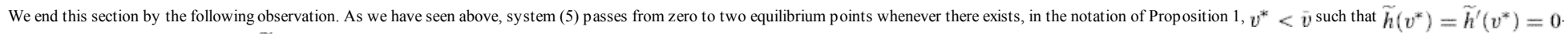

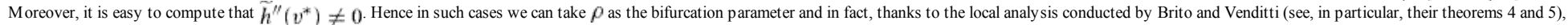

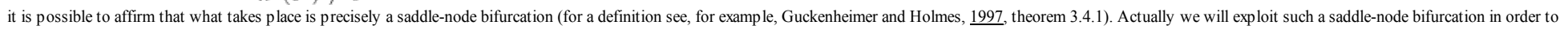
prove, in Section 5 , the occurrence of global indeterminacy in a case where two locally indeterminate equilibrium points of order 2 and 3 coexist.

\section{Global analysis in a two-dimensional context}

\section{Top of page}

2. Abstract

3. 1 Introduction

4. 2 The model

5. 3 A change of variables

6. 4 Global analysis in a two-dimensional context

7. 5 Global analysis in a three-dimensional context

8. 6 Concluding remarks

9. Appendix

10. References 
Our aim is to show, via global analysis of system (5), examples proving the occurrence of specific patterns of global indeterminacy in the above model. In fact we will consider two cases where system (5) exhibits two equilibrium

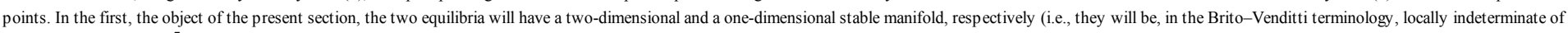

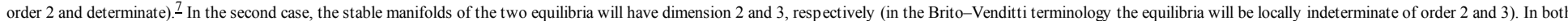

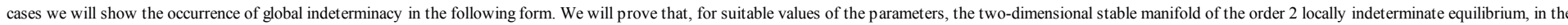

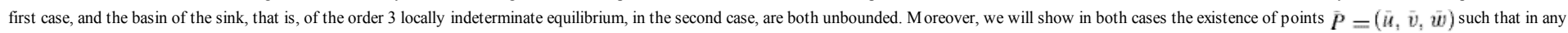
neighborhood of $\bar{P}$ lying on the plane $v=\bar{v}$ (corresponding to a fixed value of the state variable $k=k_{1} / k_{2}=K_{1} / K_{2}=e^{v}$ ) there exist points $Q$ whose positive trajectories tend to either equilibrium.

We start by stating the following result:

Proposition 4. When $\delta=0$, the plane $\left.u=\bar{d}^{(\text {recall }} \bar{d}=\left(\psi_{12}+\psi_{21}\right)^{-1} \ln \frac{c_{2}}{c_{1}}\right)$ is invariant.

Proof 3. Recall that $u=\delta v+\bar{d}$ imp lies $r_{1}(\delta v+\bar{d}, v)=r_{2}(\delta v+\bar{d}, v)$ and thus (see system (5)) $u=0$. Hence, when $\delta=0, u=\bar{d}$ is invariant. $\square$

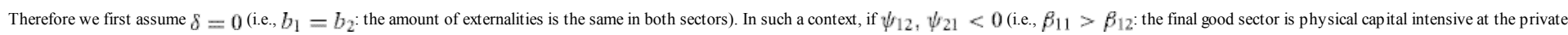

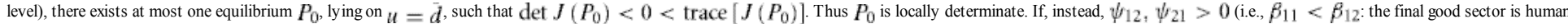

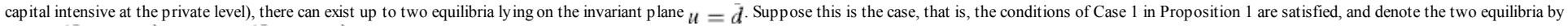
$P_{1}=\left(\bar{d}, v_{1}, w_{1}\right)$ and $P_{2}=\left(\bar{d}, v_{2}, w_{2}\right)$, with $v_{1}<v_{2}$ (note that, by (7), the growth rate $\gamma$ associated with $P_{2}$ is higher than that associated with $\left.P_{1}\right)$. Then det $J\left(P_{1}\right)>0>$ det $J\left(P_{2}\right)$, while trace $\left[J\left(P_{1}\right)\right]$, trace $\left[J\left(P_{2}\right)\right]>0$. Therefore $P_{2}$ is locally determinate, whereas $P_{1}$ can be either repelling or locally indeterminate of order 2 . Moreover, by a translation $u \rightarrow u+\bar{u}$, where $\exp \left(\psi_{12}+\psi_{21}\right) \bar{u}=\frac{c_{2}}{c_{1}}$, the original $c_{1}$ and $c_{2}$ are changed into $\overline{c_{1}}=\overline{c_{2}}$, so that $\bar{d}=0$. Consequently, the system on the invariant plane $u=0$ reduces to

$$
\left\{\begin{array}{l}
\dot{v}=\tilde{g}(v)-e^{w} \\
\dot{w}=\tilde{h}(v)
\end{array}\right.
$$

where $\vec{g}(v)=g(\delta v, v), \hat{h}(v)=h(\delta v, v)$. So, since $\delta=0$, it follows that, on the plane $u=0, \vec{g}^{\prime}(v)=\frac{\partial g}{\partial v}$ and $\tilde{h}^{\prime}(v)=\frac{\partial h}{\partial v}$. Therefore $P_{1}$ is locally indeterminate of order 2 if and only if $\frac{\partial g}{\partial v}\left(0, v_{1}\right)<0$. In fact it is easy to compute that

$$
\begin{aligned}
& \tilde{g}(v)=r(v)\left(1+e^{v}\right)\left(\psi_{12}-\psi_{21} e^{v}\right), \\
& \breve{h}(v)=e^{v}\left[-\frac{\rho}{\sigma}+r(v)\left(\frac{1}{\sigma}+\psi_{12}-1-\psi_{21} e^{v}\right)\right],
\end{aligned}
$$

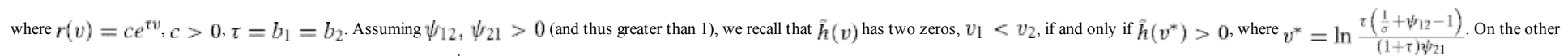
hand, the function $w=\ln g(v)$ is defined for $v<\bar{v}=\ln \frac{\psi_{12}}{\psi_{21}}$ and has a maximum at the point $v_{0}$, where $e^{v_{0}}$ is the positive solution of the equation $\psi_{21}(2+\tau) x^{2}-\left[\psi_{12}(1+\tau)-\psi_{21}\right] x-\tau \psi_{12}=0$ Hence two equilibria exist if and only if there exist $v_{1}<v_{2}$ such that $\hat{h}\left(v_{1}\right)=\hat{h}\left(v_{2}\right)=0$ and $v_{2}<\bar{v}$. Moreover, $P_{1}=\left(0, v_{1}, w_{1}\right)$ has a two-dimensional stable manifold if and only if $v_{0}<v_{1}$.

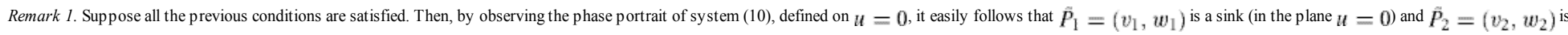

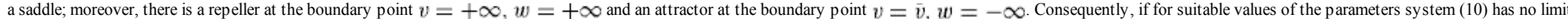

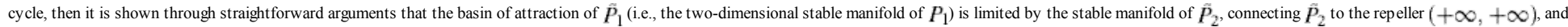
thus is unbounded. This will prove the global indeterminacy result stated at the beginning of this section.

In the following we provide conditions for the above situation to occur.

First of all, we observe that system (10) can be regarded as a Liénard system when $v \in\left(-\infty, v_{2}\right)$. To fix ideas, let us take $\tau=0.5$. We also assume, for sake of simplicity, that $\psi_{12}=\psi_{21}=\psi>1 . \stackrel{8}{\text { Then }}$

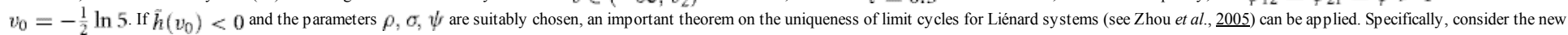
variables $x=v-v_{1}, y=w-w_{1}$ and change $t$ into $-t$. Then the following Liénard system is defined in the strip $-\infty<x<\bar{x}$, where $\bar{x}=v_{2}-v_{1}$ :

$$
\left\{\begin{array}{l}
\dot{x}=\lambda(y)-\Phi(x) \\
\dot{y}=-\gamma(x)
\end{array}\right.
$$

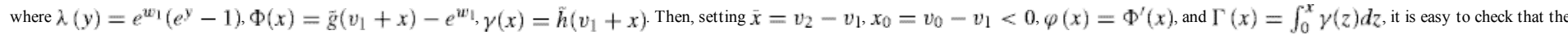
smooth system (11), defined in the strip $x \in(-\infty, \bar{x})$, satisfies:

1. $\lambda(y)$ is increasing and $y \cdot \lambda(y)>0$ when $y \neq 0$;

2. $\left(x-x_{0}\right) \cdot \varphi(x)<0$ when $x \neq x_{0}$;

3. $x \cdot \gamma(x)>0$ when $x \neq 0$.

Moreover, by (Zhou et al., 2005, theorem 3), if two further conditions are met:

1. $\frac{\varphi(x)}{\gamma(x)}$ is non-decreasing in $(-\infty, b)$, where $b \in\left(-\infty, x_{0}\right)$ is defined by $\Phi(b)=0$ (i.e., $\left.\vec{g}\left(v_{1}+b\right)=\vec{g}\left(v_{1}\right)\right)$;

2. the system of equations $\Phi(x)=\Phi(z), \Gamma(x)=\Gamma(z)$ has at most one solution for $x \in(-\infty, b), z \in(0, \bar{x})$;

then (11) has at most one limit cycle, which, if it exists, is simple (hence does not generate several limit cycles).

Example 2. In system (5), let $\delta=0, \tau=0.5, \frac{\rho}{c}=\frac{1}{\sqrt[4]{5}}, \sigma=\frac{1}{3}, \psi_{12}=\psi_{21}=1.698$. Then (5) has two equilibria, $P_{1}$ and $P_{2}$, lying on the invariant plane $u=0$ and the planar system (11) satisfies the above conditions $1-5$

The following theorem gives, on the basis of Remark 1, sufficient conditions for the basin of attraction of $P_{1}$ to be unbounded.

Theorem 1. Assume system (5) has parameters $\delta=0, \tau=0.5, \psi_{12}=\psi_{21}=\psi>1$. Assume there exist two equilibrium points $P_{1}$ and $P_{2}$ which are, for the system (10) defined on the invariant plane $u=0$, respectively a sink and a saddle. Then, if the planar system (11) satisfies conditions $1-5$, no limit cycle exists and consequently the basin of attraction of $P_{1}$, lying on the plane $u=0$, is unbounded.

Proof 4. See the Appendix. $\square$

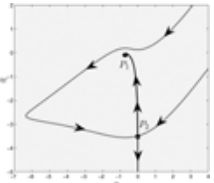

Figure 1. Numerical simulation of the phase portrait of system $\underline{(10)}$ with parameter values satisfying the conditions of Theorem 1. The unbounded basin of attraction in the invariant plane $u=0$ of the equilibrium $P_{1}$ (which is a poverty trap) is limited by the one-dimensional stable manifold of the determinate equilibrium $P_{2}$. Parameter values: $\psi=1.698, \sigma=\frac{1}{3}, \tau=0.5, \rho=\frac{1}{\sqrt[4]{5}}$.

Download figure to PowerPoint (/doi/10.1111/ijet.12042/figure.pptx? figureAssetHref=image n/ijet12042-fig-0001.png)

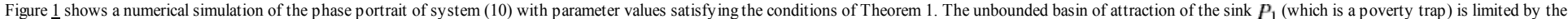
one-dimensional stable manifold of $P_{2}$. Notice that, if the initial value $v(0)$ of the predetermined variable $v$ is high enough, then there exists a continuum of initial values $w^{*}=w(0)$ of the jumping variable $w$ such that the

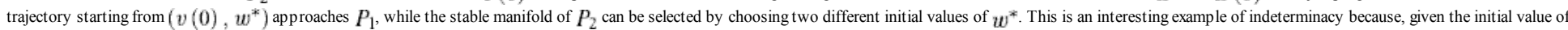


$v$, the economy can approach the locally determinate equilibrium $P_{2}$ by following rather different transition paths. Observe that in this case we possess a full description of the unbounded basin of $P_{1}$ (on the plane $u=0$ ) and therefore of the global indeterminacy scenario. Finally, notice that, as in Matsuy ama (1991) and Antoci et al. (2011), the poverty trap $P_{1}$ can be reached even if the initial value $v(0)$ coincides with the value assumed by the predetermined variable $v$ at the locally determined equilibrium $P_{2}$; symmetrically, $P_{2}$ can be reached even if the economy starts with an initial value of $v$ coinciding with that of the poverty trap $P_{1}$.

In the above context, still denoting by $v_{1}<v_{2}$ the zeros of $\tilde{h}(v)$ for $v \in\left(v_{0}, 0\right)$, we can move $v_{1}$ (e.g., by suitably varying $\rho$ and/or $\sigma$ ) until it crosses the value $v_{0}$, causing (generically) a Hopf bifurcation to occur. The following proposition holds:

Proposition 5. Under our assumptions, when $v_{1}$ crosses the value $v_{0}$, the Hopf bifurcation occurs and is supercritical (i.e., an attracting limit cycle arises around $\tilde{P}_{1}$ when it becomes a source).

Proof 5. See the Appendix. $\square$

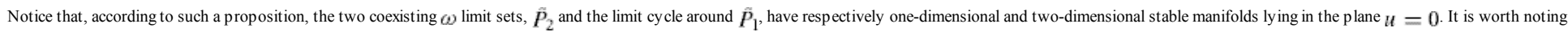

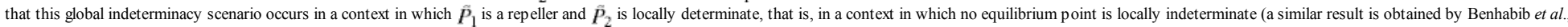

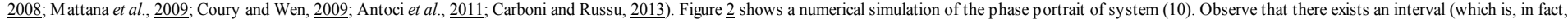
unbounded) of values of the predetermined variable $v$ from which the economy can approach either $\tilde{P}_{2}$ or the limit cycle around $\tilde{P}_{1}$, according to the initial choice of the jumping variable $w$ (the initial value of the other jumping

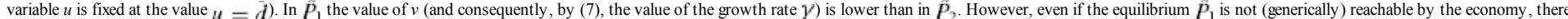

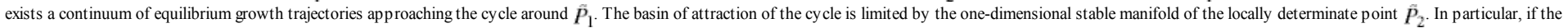

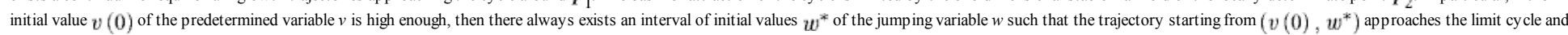

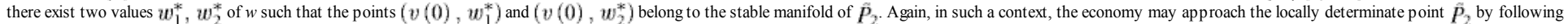
rather different transition paths according to the initial choice $\left(w_{1}^{*}\right.$ or $\left.w_{2}^{*}\right)$ of $w$.

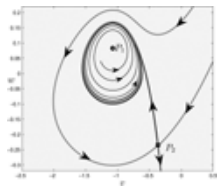

Figure 2. Global indeterminacy scenario in which two $\omega$-limit sets exist, $\tilde{P}_{2}$ and the limit cycle around $\tilde{P}_{1}$, having respectively one-dimensional and two-dimensional stable manifolds lying in the plane $u=0$. The (unbounded) basin of attraction of the limit cycle is limited by the one-dimensional stable manifold of the locally determinate point $\tilde{P}_{2}$. Parameter values: $\tau=0.3, c=1, \psi=1.698, \sigma=\frac{1}{3}$, $\rho=0.752877378571337$.

Download figure to PowerPoint (/doi/10.1111/ijet.12042/figure.pptx?

figureAssetHref=image_n/ijet12042-fig-0002.png)

\title{
5 Global analysis in a three-dimensional context
}

\author{
1. Top of page \\ 2. Abstract \\ 3. 1 Introduction \\ 4. 2 The model \\ 5. 3 A change of variables \\ 6. 4 Global analysis in a two-dimensional context \\ 7. 5 Global analysis in a three-dimensional context \\ 8. 6 Concluding remarks \\ 9. Appendix \\ 10. References
}

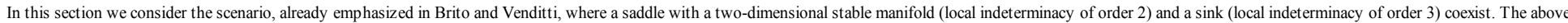

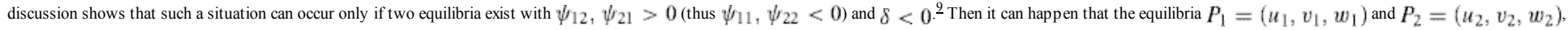
$u_{1}>u_{2}$ and $v_{1}<v_{2}$, are respectively, as we said, a saddle endowed with a two-dimensional stable manifold and a sink.

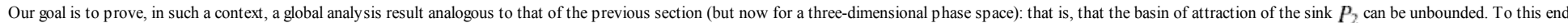
we will consider the case where $P_{1}$ and $P_{2}$ split, through a saddle-node bifurcation, from a degenerate equilibrium $P_{0}$. More precisely, we can take $\rho$ as a bifurcation parameter. Then Example 3 below shows that for a suitable

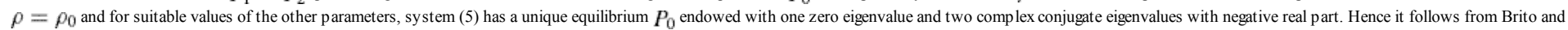

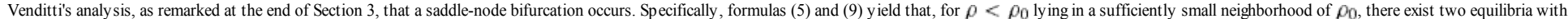

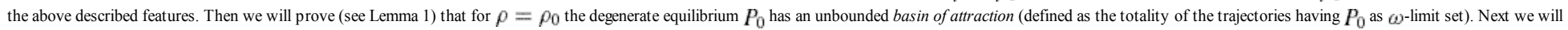
prove (see Theorem 1) that such a property is conserved, after the bifurcation, by the sink $P_{2}$.

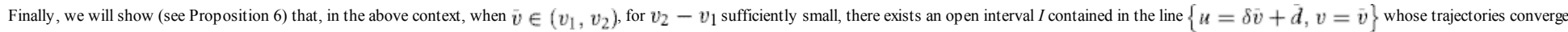

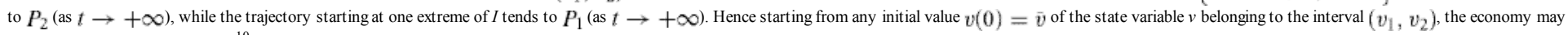

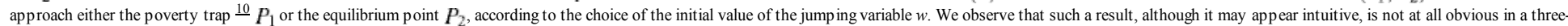
dimensional phase space.

Let us start with the following example

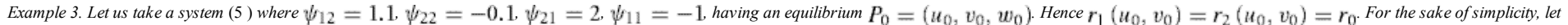

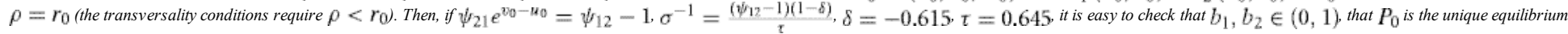
of (5) and, finally, that the Jacobian matrix $J\left(P_{0}\right)=J_{0}$ has one zero eigenvalue and two complex conjugate eigenvalues with negative real part.

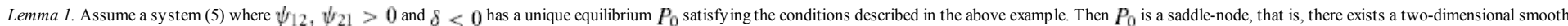

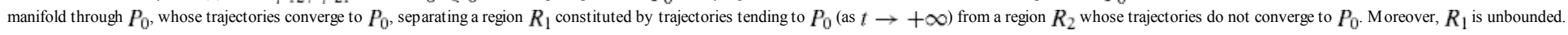

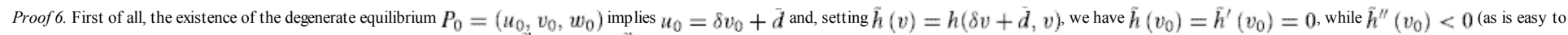

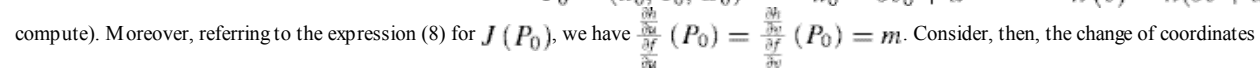

$$
x=u-u_{0}, y=v-v_{0}, z=w-w_{0}-m\left(u-u_{0}\right) .
$$

In the new coordinates, $P_{0}=O=(0,0,0)$ and

$$
J(O)=\left(\begin{array}{ccc}
a & b & 0 \\
-c & -d & -l \\
0 & 0 & 0
\end{array}\right)
$$


where $a, b, c, d, e>0, a<d$ and $(d-a)^{2}<4(b c-a d)$. In fact, multiplying the vector field of the system, in the new coordinates, by $e^{-m x}$, we obtain a system similar to (5):

$$
\left\{\begin{array}{l}
\dot{x}=p(x, y) \\
\dot{y}=q(x, y)-l e^{z} \\
\dot{z}=s(x, y)
\end{array}\right.
$$

where $O=(0,0,0)$ is the unique equilibrium, $\frac{\partial s}{\partial x}(0,0)=\frac{\partial s}{\partial y}(0,0)=0$ and, since $\hat{h}^{\prime \prime}\left(v_{0}\right)<0$,

$$
\left(\frac{\partial^{2} s}{\partial x^{2}} \delta^{2}+2 \frac{\partial^{2} s}{\partial x \partial y} \delta+\frac{\partial^{2} s}{\partial y^{2}}\right)(0,0)<0 .
$$

Moreover, when $z=-\ln l+\ln q(\delta y, y)=\varphi(y)$, it is easy to check that inline image and inline image.

From straightforward computations it follows that the eigenline associated with the zero eigenvalue of inline image is given by inline image, while the eigenplane associated with the complex conjugate eigenvalues of inline image is inline image. Now take a sufficiently small neighborhood $N$ of $O$. From previous considerations it follows that there exists a two-dimensional smooth manifold $S$, whose trajectories converge to $O$, which

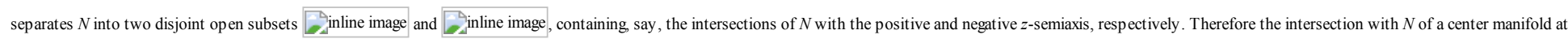
$O$ of (14), tangent to inline image in $O$, can be written as inline image, 2 inline image, inline image. Besides, straightforward calculations show that, if $N$ is small enough, the coordinates of

$$
\text { Risplay math }
$$

where inline image. More precisely, it can be shown that for a sufficiently small $N$ the equations of a center manifold inline image (i.e., of an invariant manifold tangent in $O$ to the line $L$ ) are of the type inline image, inline image, with 2 inline image and inline image smooth in a neighborhood of 2 inline image. Moreover, the center manifold is proven to be unique (see the Appendix).

It follows that along 2 inline image, 2 inline image increases while 2 inline image and 2 inline image decrease (recall that (15) holds)

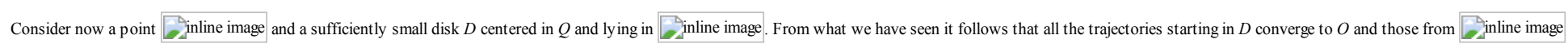

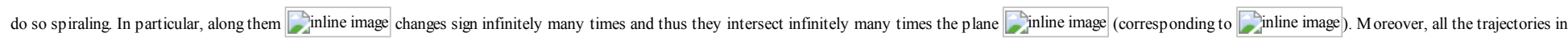
inline image converge to $O$ (if $N$ is small enough), as they cross inline image alternately on each side of the line $L$ and therefore eventually wind around ${ }_{2}$ inline image and so spiral toward $O$.

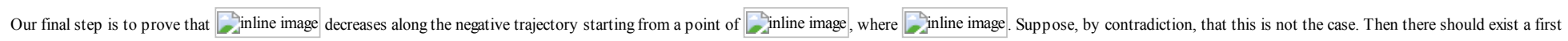

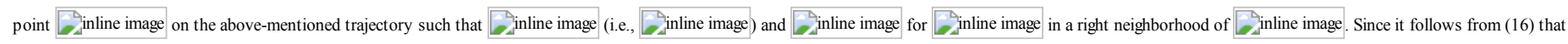
Ainline image when inline image, we have:

\section{display math}

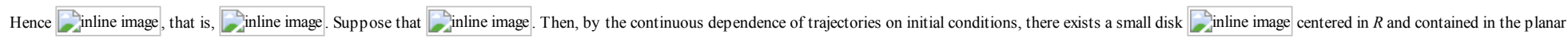

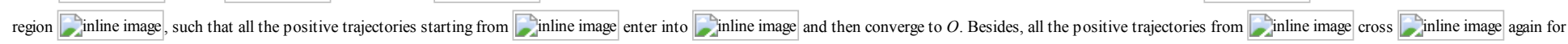

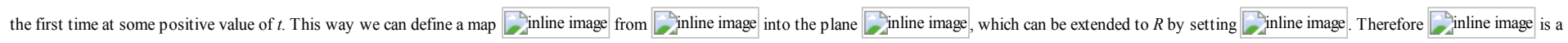

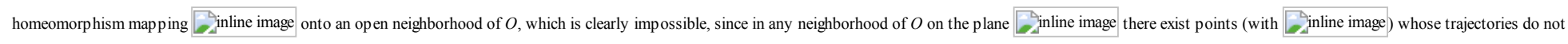
converge to $O$. Hence 2 inline image. Therefore, since inline image, it follows that winline image, while

$$
\text { Rdisplay math }
$$

Hence inline image both in a left and a right neighborhood of inline image, which leads to a contradiction. Consequently it can be proven (see the Appendix) that along the above trajectory (say, the continuation of inline image ) $x, y$ and $z$ are all unbounded: specifically, coming back to the original time $t$,

\section{display math}

This completes the proof of the lemma.

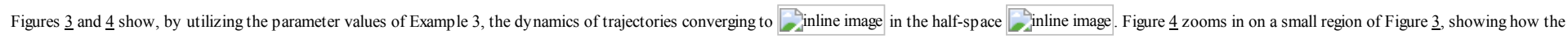
generic trajectory converging to inline image winds around the center manifold through inline image.

Figure 3. The dynamics of trajectories converging to sinline image in the half-space sinline image, utilizing the parameter values of Example 3. Parameter values: 2 inline image, 2 inline image, Sinline image, Sinline image, rinline image, rinline image, Sinline image.

Download figure to PowerPoint (/doi/10.1111/ijet.12042/figure.pptx? figureAssetHref=image n/ijet12042-fig-0003.png)

Figure 4. Close-up of the small region indicated in Figure $\underline{3}$, showing how the generic trajectory converging to inline image winds around the central manifold. 


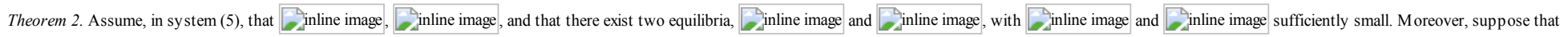
inline image has a two-dimensional stable manifold, Ainline image is a sink and both the Jacobian matrices inline image and inline image have two complex conjugate eigenvalues. Then the basin of attraction of inline image is unbounded.

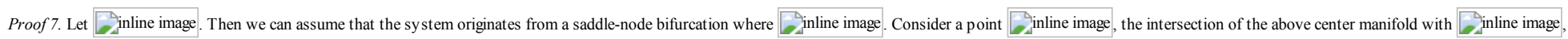

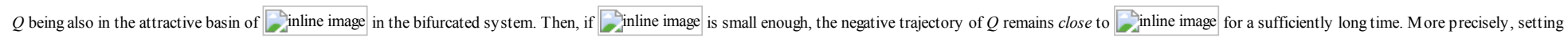
inline image, we can take, for a sufficiently small inline image, some inline image sufficiently large that, denoting inline image, the following inequalities hold:

1. Sinline image;

2. Sinline image (recall that sinline image and inline image when $v$ is large enough);

3. Sinline image.

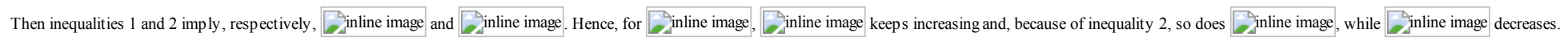
It follows, by the same arguments used in the Appendix, that such a trajectory is unbounded and, therefore, so is the basin of attraction of inline image.

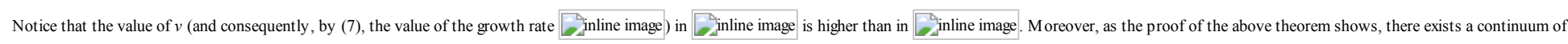

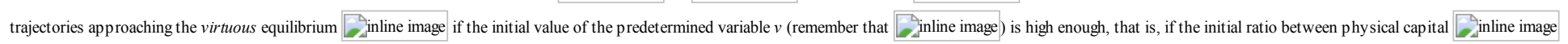
and human capital inline image is high enough.

Finally, we prove the following proposition:

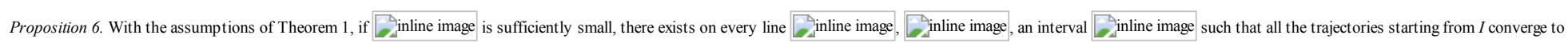
inline image, while the trajectory starting from either $A$ or $B$ converges to inline image.

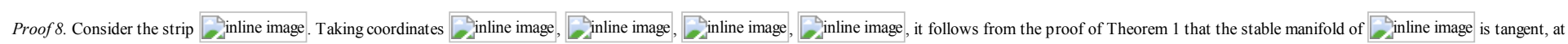

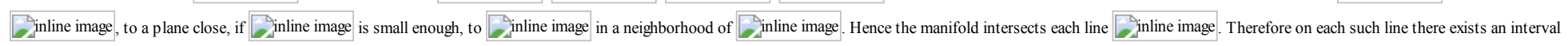
with the properties described in the statement of the proposition. inline image

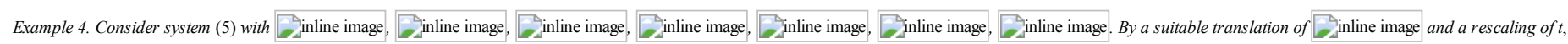

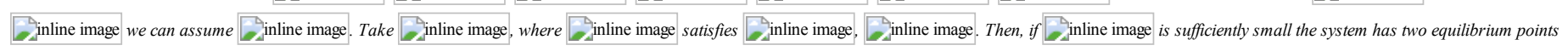
inline image and anline image, with inline image, satisfying the conditions of Theorem 1. Hence inline image is a saddle with a two-dimensional stable manifold and ainline image is a sink.

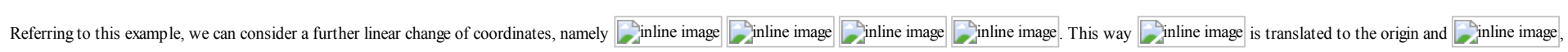
inline image lie on 2 inline image. On such a plane a line 2 inline image represents a fixed choice of the state variable. Then let $z$ vary on a line inline image: for a suitable value of $z$ close to 0 , say inline image, the

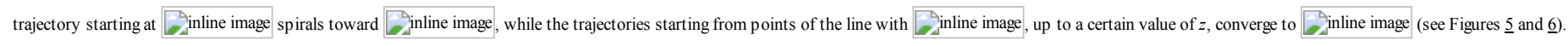

\section{Simage}

Figure 5. Two trajectories starting from the same initial value of the state variable 2 inline image (remember that inline image). The trajectory starting from inline image, with inline image, approaches the saddle 2 inline image; the trajectory converging to the locally attractive equilibrium Sinline image starts from inline image, with inline image. The parameter values are those given in Example 4 with 2 inline image.

Download figure to PowerPoint (/doi/10.1111/ijet.12042/figure.pptx? figureAssetHref=image_n/ijet12042-fig-0005.png)

image

Figure 6. Phase portrait of system (5) obtained with the same parameter values of the simulation in Figure $\underline{5}$. Only one trajectory (the same as illustrated in Figure $\underline{5}$ ) approaches the saddle 2 inline image; the other trajectories, starting from inline image with inline image, belong to the basin of attraction of the equilibrium sinline image.

Download figure to PowerPoint (/doi/10.1111/ijet.12042/figure.pptx? figureAssetHref=image n/ijet12042-fig-0006.png)

Figures $\underline{5}$ and $\underline{6}$ illustrate the phase portrait of system (5) with the parameter values of the above example. Figure $\underline{5}$ shows two trajectories starting from the same initial value of the state variable 2 inline image (remember that

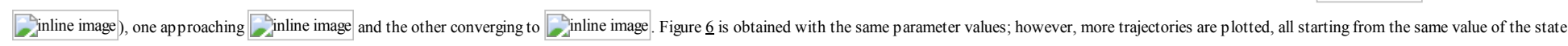
variable $y$. In Figure $\underline{6}$ only one trajectory app roaches 2 inline image, while the others belong to the basin of attraction of the virtuous equilibrium 2 inline image.

\section{Concluding remarks}

\section{Top of page}


2. Abstract

3. 1 Introduction

4. 2 The model

5. $3 \mathrm{~A}$ change of variables

6. 4 Global analysis in a two-dimensional context

7. 5 Global analysis in a three-dimensional context

8. 6 Concluding remarks

9. Appendix

10. References

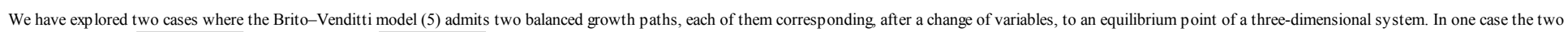

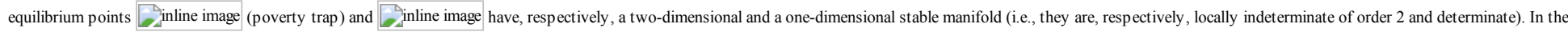

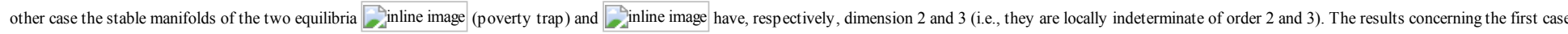

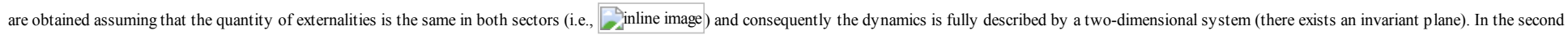
case the dimension of system (5) cannot be reduced. In both cases, for suitable values of the parameters, we have proved:

1. The existence of points inline image inline image such that in any neighborhood of inline image lying on the plane inline image (corresponding to a fixed value of the state variable 2 inline image) there exist points $Q$ whose positive trajectories tend to either equilibrium (these results are illustrated in Figures $\underline{1}, \underline{2}, \underline{5}$, and $\underline{6}$ ).

2. The unboundedness of the basin of attraction of the locally indeterminate second-order equilibrium in the first case, and of the locally indeterminate third-order equilibrium in the second case. This result appears to contain more information than other global indeterminacy results, where the equilibrium is shown to be globally indeterminate in the interior of a two-dimensional invariant region enclosed by a periodic or homoclinic orbit (see, for example, Benhabib et al., 2008; Mattana et al., 2009).

3. The basins of attraction of the equilibrium point dinline image (in the first case) and of the point inline image (in the second case) are limited respectively by the onedimensional stable manifold of 2 inline image and by the two-dimensional stable manifold of 2 inline image.

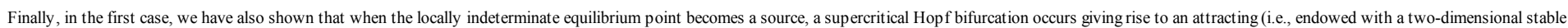
manifold) limit cycle (see Figure 2). When this happens, global indeterminacy is observed in a context where no equilibrium point is locally indeterminate.

\section{Appendix}

1. Top of page

2. Abstract

3. 1 Introduction

4. 2 The model

5. 3 A change of variables

6. 4 Global analysis in a two-dimensional context

7. 5 Global analysis in a three-dimensional context

8. 6 Concluding remarks

9. Appendix

10. References

\section{Proof of Proposition 2}

Let inline image be an equilibrium of (5). Then inline image, as can easily be checked. From straightforward computations it follows that

display math

Hence the coefficient of 2 inline image is positive, being equal to 2 inline image, and so is the coefficient of $t_{4}$ inline image, as inline image. Moreover,

display math

This proves the proposition. 2 inline image

\section{Proof of Proposition 3}

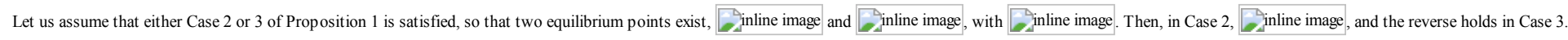

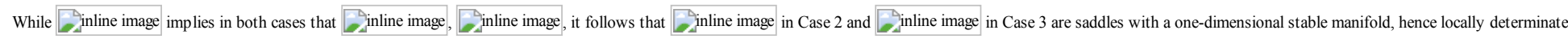
When 2 inline image, writing the characteristic polynomial as 2 inline image, where, of course, inline image, it follows from straightforward computations that two negative real part eigenvalues exist if and only if

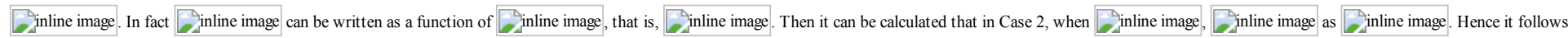
that 2 inline image is a source. In Case 3, on the other hand, inline image can be locally indeterminate of order 2, as Example 1 shows. ${ }_{2}$ inline image 


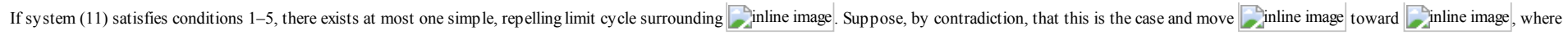

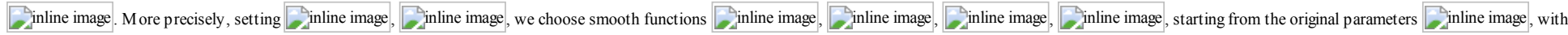

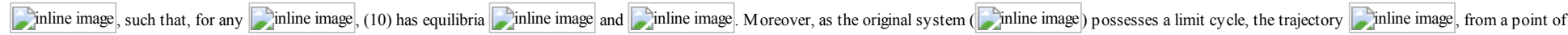

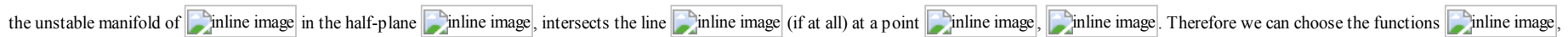

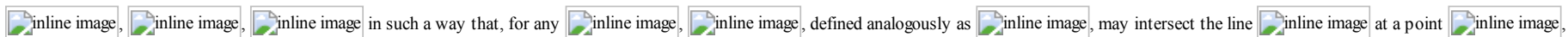

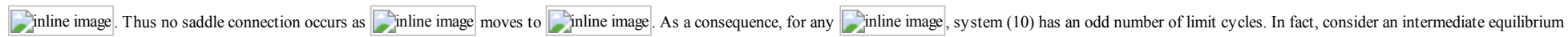

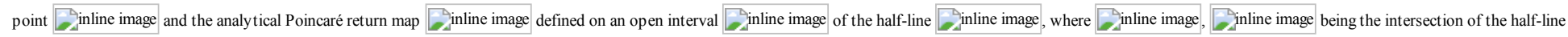

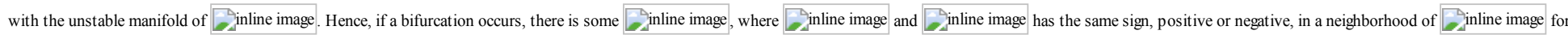

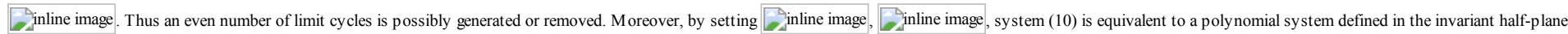
inline image, which has a finite number of limit cycles (see, for example, Arnold and Il'y ashenko, 1994). Finally, as proven in Proposition 5, a further limit cycle is generated by the Hopf bifurcation when 2 inline image is

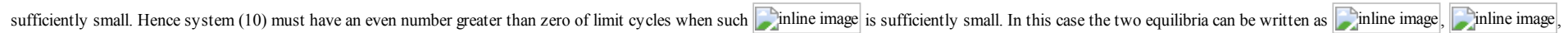

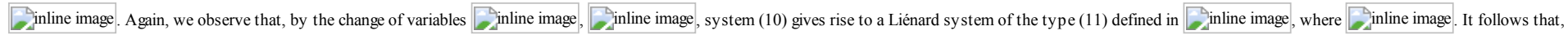
when inline image is small enough, this system has at most one simple limit cycle if:

1. Sinline image is non-increasing in inline image;

2. the system of equations 2 inline image, $r$ inline image has at most one solution for sinline image, $\sigma$ inline image.

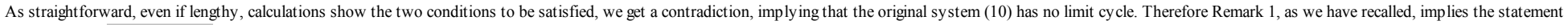
of the theorem. Ainline image

\section{Proof of Proposition 5}

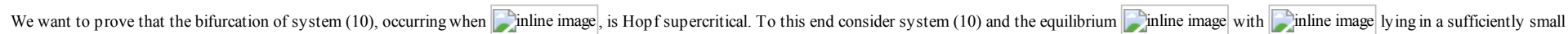
neighborhood of inline image. Then the eigenvalues at 2 inline image are given, as can easily be computed, by

\section{display math}

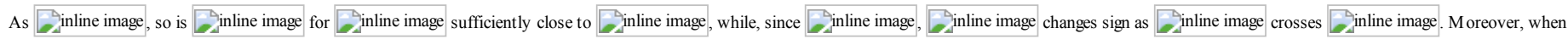

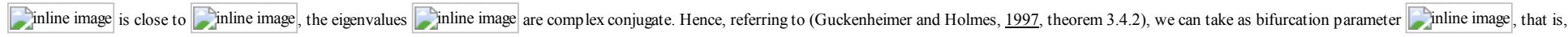
we can set 2 inline image. Therefore

display math

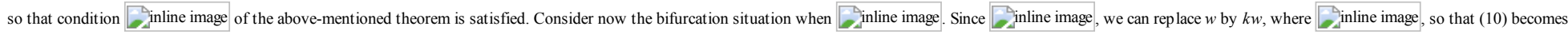

$$
\text { display math }
$$

This way the system is in the form

display math

where 2 inline image. Then we can apply (Guckenheimer and Holmes, 1997, formula (3.4.11)) in order to calculate the quantity $a$ which yields a Hopf supercritical ( 2 inline image) or a Hopf subcritical ( 2 inline image) bifurcation. In fact straightforward computations lead to

display math

As it can easily be checked that

$$
\text { Rdisplay math }
$$

this proves that a Hopf supercritical bifurcation occurs. inline image

\section{Uniqueness of the center manifold in Lemma 1}

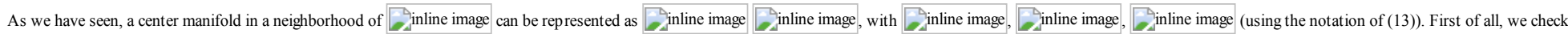
that 2 inline image are 2 inline image in a suitable interval 2 inline image, $C_{2}$ inline image. In fact, by induction, let

$$
\text { display math }
$$

inline image. Then, differentiating, we have

$$
\text { display math }
$$


where 2 inline image are determined by 2 inline image. So also inline image are unequivocally determined.

However, this does not guarantee that the center manifold is analy tic and thus unique. Let us therefore assume, by contradiction, that there exist infinitely many center manifolds. In fact we can confine ourselves to considering inline image, as for tinline image a trajectory lying on the center manifold tends to $O$ as inline image, which implies that the center manifold in such half-space is unique Sijbrand (1985).

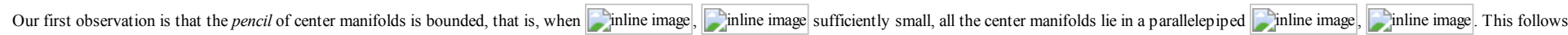

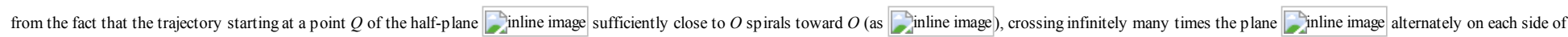
the curve inline image and thus of the line 2 inline image. Hence the pencil of center manifolds lies inside this spiral.

Next we show that each center manifold inline image satisfies, in a suitable interval inline image, a second-order differential equation inline image. To this end, from (20) we derive

Rdisplay math

that is,

Rdisplay math

On the other hand, inline image y ields inline image, from which we get inline image as a function of inline image. Therefore, differentiating with respect to $y$, a series of easy steps leads to

Rdisplay math

Next we want to show that we can write

display math

where 2 inline image and 2 inline image are smooth and non-zero in a neighborhood of 2 inline image. In fact, for any inline image, let

Rdisplay math

where inline image are the same for any inline image. From what we have observed, we can consider, in a suitable interval inline image, the lowest center manifold with respect to $x$, that is, inline image such that

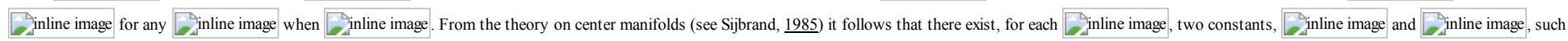
that

Rdisplay math

where 2 inline image and 2 inline image. By differentiating with respect to $y$, we can calculate 2 inline image and inline image, and in fact we can write

Risplay math

Analogously,

display math

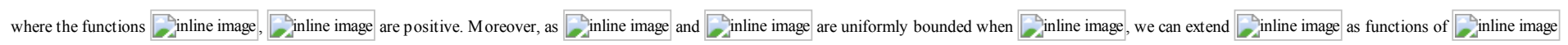
defined in a suitable neighborhood of inline image. Clearly these functions may not be continuous in 2 inline image. However, for any 2 inline image, the functions defined as

Rdisplay math

when 2 inline image, and 0 when 4 inline image, are smooth in a neighborhood of 2 inline image. Then, recalling 2 inline image, (22) follows from straightforward computations. Hence

display math

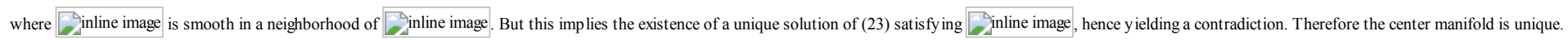

\section{Unbounded trajectory converging to inline image in Lemma 1}

Let 2 inline image, the intersection of the unique center manifold with the half-space inline image. Exchanging $t$ with 2 inline image, we have proved that the trajectory starting at $Q$ satisfies ${ }_{A}$ inline image when

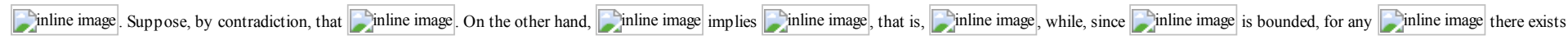

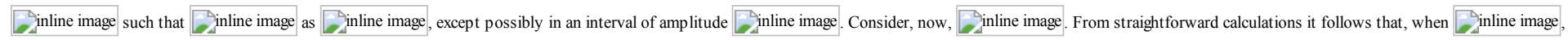
except possibly in an interval of amplitude 2 inline image

display math 


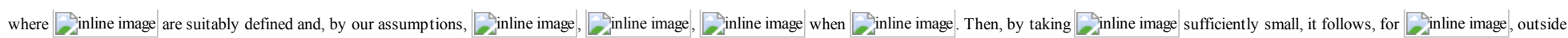

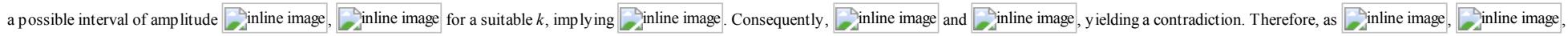
so that inline image tends to inline image, and it can be easily seen that inline image does likewise.

Notes

1 See Benhabib and Farmer (1999). Although the main body of the literature on local indeterminacy is concerned with economies with increasing social returns (see, for example, Benhabib and Farmer, 1994; Boldrin and Rustichini, 1994), a growing proportion of articles deal with models where indeterminacy is obtained under the assumption of social constant return technologies (see Benhabib and Farmer, 1999; Mino, 2001; Mino et al., 2008).

2 In particular, local indeterminacy occurs if the number of eigenvalues with negative real parts of the linearization matrix evaluated at the equilibrium point is greater than the number of state variables. So, in a two-dimensional system, we have local indeterminacy if and only if the equilibrium point is a sink.

3 In the present work we do not deal with another important problem in economic dynamics, namely the existence of indifference points in an optimal control problem. Starting from these points, more than one optimal solution exists, giving rise to the same value of the objective function (see the seminal contributions of Skiba, 1978 ; Dechert and Nishimura, 1983; Sethi, 1997). In our context, the trajectories followed by the economy do not represent optimal solutions, the dynamics being conditioned by externalities. Therefore, when multiple equilibrium trajectories exist, starting from the same initial values of the state variables, economic agents may select one trajectory along which the value of the objective function is lower than along other admissible trajectories, due to coordination problems.

4 The long run behaviors of the state variables may be different also when there exists a chaotic attractor (see, e.g., Boldrin et al., 2001; Antoci et al., 2010, 2014; Gori and Sodini, 2011, 2014).

5 Where inline image represents the equilibrium rental rate inline image, 2 inline image.

6 The relevance, with respect to the existing literature, of the local analysis results illustrated in this section is exhaustively discussed in Brito and Venditti's article.

7 Notice that, in system (5), $v$ is a state variable while $u$ and $w$ can be considered as jumping variables. So, an equilibrium point is locally determinate if it has a onedimensional stable manifold or is repelling.

8 Remember that 2 inline image and inline image.

9 Remember that inline image if and only if 2 inline image, that is, if the final good is intensive in human capital at the private level.

10 Remember that, by (7), the growth rate inline image associated with each equilibrium point is positively correlated with the equilibrium value of $v$.

\section{References}

1. Top of page

2. $\underline{\text { Abstract }}$

3. 1 Introduction

4. 2 The model

5. 3 A change of variables

6. 4 Global analysis in a two-dimensional context

7. 5 Global analysis in a three-dimensional context

8. 6 Concluding remarks

9. Appendix

10. References

Antoci, A., M. Galeotti, P. Russu (2011), Poverty trap and global indeterminacy in a growth model with open-access natural resources, Journal of Economic Theory 146, 569-91.

CrossRef (/resolve/reference/XREF?id=10.1016/j.jet.2010.12.003), Web of Science ${ }^{\circledR}$ Times Cited: 5 (/resolve/reference/ISI?id=000289597900007)

- Go here for SFX (http://192.167.125.34:9003/unif?url ver=Z39.882004\&rft_val_fimt=info $\% 3 \mathrm{Aofi} \% 2 \mathrm{Ffint} \% 3 \mathrm{Akev} \% 3 \mathrm{Amtx} \% 3 \mathrm{Ajournal} \& \mathrm{rft}$.genre=article\&rft.jitle=Journal\%20of\%20Economic\%20Theory\&rft.atitle=Poverty

Antoci, A., M. Sodini, and A. Naimzada (2010), Bifurcations and chaotic attractors in an overlapping generations model with negative environmental externalities, G. Bischi, C. Chiarella, and L. Gardini, eds, Nonlinear Dynamics in Economics, Finance and Social Sciences, 39-53, Berlin: Springer-Verlag. CrossRef (/resolve/reference/XREF?id=10.1007/978-3-642-04023-8_3), Web of Science ${ }^{\circledR}$ Times Cited: 2 (/resolve/reference/ISI?id=000288049500003)

- Go here for SFX (http://192.167.125.34:9003/unifi?url ver=Z39.882004\&rft val fimt $=$ info $\% 3$ Aofi $\% 2 \mathrm{Ffmt} \% 3 \mathrm{Akev} \% 3 \mathrm{Amtx} \% 3 \mathrm{Ajournal} \& \mathrm{rft}$. genre $=$ article\&rft.jtitle $=$ Nonlinear $\% 20 \mathrm{Dynamics} \% 20 \mathrm{in} \% 20 \mathrm{Economics} \% 2 \mathrm{C} \% 20 \mathrm{Fir}$

Antoci, A., M. Sodini, and L. Zarri (2014), Relational consumption and nonlinear dynamics in an overlapping generations model, Decisions in Economics and

Finance 37, 137-58

CrossRef (/resolve/reference/XREF?id=10.1007/s10203-013-0147-9)

- Go here for SFX (http:/192.167.125.34:9003/unifi?url_ver=Z39.882004\&rft val fimt=info $\% 3$ Aofi $\% 2 \mathrm{Ffmt} \% 3 \mathrm{Akev} \% 3 \mathrm{Amtx} \% 3$ Ajournal\&rft.genre=article\&rft.jtitle=Decisions $\% 20 \mathrm{in} \% 20 \mathrm{Economics} \% 20 \mathrm{and} \% 20 \mathrm{Finance} \& \mathrm{rft} . \mathrm{at}$

Arnold, V. I., and Yu. S. Il'yashenko (1994), Ordinary differential equations, D. V. Anosov, and V. I. Arnold, eds, Dynamical Systems I, Berlin: Springer-Verlag. - Go here for SFX (http://192.167.125.34:9003/unifi?url_ver=Z39.882004\&rft val fimt=info $\% 3$ Aofi $\% 2 \mathrm{Ffmt} \% 3 \mathrm{Akev} \% 3 \mathrm{Amtx} \% 3$ Ajournal\&rft.genre=article\&rft.jtitle=Dynamical $\% 20$ Systems $\% 20 \mathrm{I} \& \mathrm{rft}$. atitle $=$ Ordinary $\% 20 \mathrm{differ}$

Basu, S., and J. Fernald (1997), Returns to scale in US production: Estimates and implications, Journal of Political Economy 105, $249-83$. CrossRef(/resolve/reference/XREF?id=10.1086/262073), Web of Science ${ }^{\circledR}$ Times Cited: 354 (/resolve/reference/ISI?id=A1997WT04200002)

- Go here for SFX (http://192.167.125.34:9003/unifi?url ver=Z39.88- 
2004\&rft val fimt=info\%3Aofi $\% 2 \mathrm{Ffmt} \% 3 \mathrm{Akev} \% 3 \mathrm{Amtx} \% 3 \mathrm{Ajournal \& rft.genre=article \& rft.jitlle=Journal} \% 20 \mathrm{of} \% 20 \mathrm{Political} \% 20$ Economy\&rft.atitle=Returns

Benhabib, J., and S. Eusepi (2005), The design of monetary and fiscal policy: A global perspective, Journal of Economic Theory 123, 40-73.

CrossRef(/resolve/reference/XREF?id=10.1016/j.jet.2005.01.001), Web of Science $®$ Times Cited: 28 (/resolve/reference/ISI?id=000230054400004)

- Go here for SFX (http://192.167.125.34:9003/unifi?url ver=Z39.88-

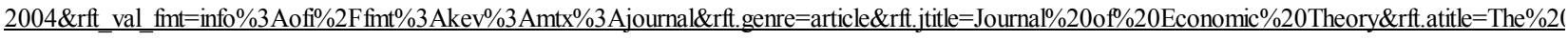

Benhabib, J., and R. E. Farmer (1994), Indeterminacy and increasing returns, Journal of Economic Theory 63, 19-41.

CrossRef(/resolve/reference/XREF?id=10.1006/jeth.1994.1031), Web of Science ${ }^{\circledR}$ Times Cited: 302 (/resolve/reference/ISI?id=A1994NU76900002)

- Go here for SFX (http:/192.167.125.34:9003/unifi?url ver=Z39.88-

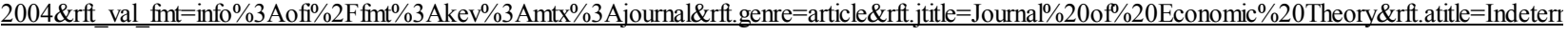

Benhabib, J., and R. E. Farmer (1999), Indeterminacy and sunspots in macroeconomics, J. B. Taylor, and M. Woodford, eds, Handbook of Macroeconomics, 387-448, Amsterdam: North-Holland.

CrossRef(/resolve/reference/XREF?id=10.1016/S1574-0048(99)01009-5)

- Go here for SFX (http://192.167.125.34:9003/unifi?url_ver=Z39.88-

$2004 \& \mathrm{rft}$ val fimt $=$ info $\% 3 \mathrm{Aofi} \% 2 \mathrm{Ffmt} \% 3 \mathrm{Akev} \% 3 \mathrm{Amtx} \% 3 \mathrm{Ajournal} \& \mathrm{rft}$. genre $=$ article $\& \mathrm{rft} . j \mathrm{titl}=$ Handbook $\% 20$ of $\% 20 \mathrm{Macroeconomics} \& \mathrm{rft}$. atitle $=$ Indeterm

Benhabib, J., and K. Nishimura (1998), Indeterminacy and sunspots with constant returns, Journal of Economic Theory 81, 58-96.

CrossRef(/resolve/reference/XREF?id=10.1006/jeth.1998.2414), Web of Science $®$ Times Cited: 95 (/resolve/reference/ISI?id=000075052300004)

- Go here for SFX (http://192.167.125.34:9003/unifi?url_ver=Z39.88-

2004\&rft val fimt=info $\% 3$ Aofi $\% 2 \mathrm{Ffmt} \% 3 \mathrm{Akev} \% 3 \mathrm{Amtx} \% 3$ Ajournal\&rft.genre=article\&rft.jtitle=Journal $\% 20$ of $\% 20 \mathrm{Economic} \% 20 \mathrm{Theory} \& \mathrm{rft}$.atitle=Indeterr

Benhabib, J., K. Nishimura, and T. Shigoka (2008), Bifurcation and sunspots in the continuous time equilibrium model with capacity utilization, International

Journal of Economic Theory 4, 337-55.

Direct Link:

- $\operatorname{Abstract}(/$ doi/10.1111/j.1742-7363.2008.00083.x/abstract)

- Full Article (HTML) (/doi/10.1111/j.1742-7363.2008.00083.x/full)

- $\operatorname{PDF}(224 \mathrm{~K})(/ \mathrm{doi} / 10.1111 / \mathrm{j} .1742-7363.2008 .00083 . \mathrm{x} / \mathrm{epdf})$

- $\operatorname{PDF}(224 \mathrm{~K})(/ \mathrm{doi} / 10.1111 / \mathrm{j} .1742-7363.2008 .00083 . \mathrm{x} / \mathrm{pdf})$

- $\underline{\text { References (/doi/10.1111/j.1742-7363.2008.00083.x/references) }}$

- Web of Science ${ }^{\circledR}$ Times Cited: 6 (/resolve/reference/ISI?id=000261805600012)

- Go here for SFX (http://192.167.125.34:9003/unifi?url ver=Z39.88-

2004\&rft val fmt $=$ info $\% 3$ Aofi $\% 2 \mathrm{Ffmt} \% 3 \mathrm{Akev} \% 3 \mathrm{Amtx} \% 3 \mathrm{Ajournal} \& \mathrm{rft}$.genre=article\&rft.jtitle=International $\% 20 \mathrm{Journal} \% 20 \mathrm{of} \% 20 \mathrm{Economic} \% 20 \mathrm{Theory} \&$

Boldrin, M., K. Nishimura, T. Shigoka, and M. Yano (2001), Chaotic equilibrium dynamics in endo-genous growth models, Journal of Economic Theory 96,

97-132.

CrossRef(/resolve/reference/XREF?id=10.1006/jeth.2000.2677), Web of Science ${ }^{\circledR}$ Times Cited: 15 (/resolve/reference/ISI?id=000167081700005)

- Go here for SFX (http://192.167.125.34:9003/unifi?url ver=Z39.88-

2004\&rft val fint=info $\% 3$ Aofi $\% 2 \mathrm{Ffmt} \% 3 \mathrm{Akev} \% 3 \mathrm{Amtx} \% 3$ Ajournal\&rft.genre=article\&rft.jtitle=Journal $\% 20$ of $\% 20$ Economic $\% 20 \mathrm{Theory} \& \mathrm{rft}$.atitle=Chaotic

Boldrin, M., and A. Rustichini (1994), Indeterminacy of equilibria in models with infinitely-lived agents and external effects, Econometrica 62, 323-42.

CrossRef (/resolve/reference/XREF?id=10.2307/2951615), Web of Science ${ }^{\circledR}$ Times Cited: 101 (/resolve/reference/ISI?id=A1994ND22400003)

- Go here for SFX (http://192.167.125.34:9003/unifi?url ver=Z39.88-

2004\&rft val fimt=info $\% 3$ Aofi $\% 2 \mathrm{Ffmt} \% 3 \mathrm{Akev} \% 3 \mathrm{Amtx} \% 3 \mathrm{Ajournal} \& \mathrm{rft}$.genre=article\&rft.jtitle=Econometrica\&rft.atitle=Indeterminacy $\% 20 \mathrm{of} \% 20$ equilibria

Brito, P., and A. Venditti (2010), Local and global indeterminacy in two-sector models of endogenous growth, Journal of Mathematical Economics 46, 893-911.

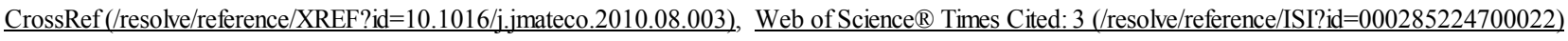

- Go here for SFX (http://192.167.125.34:9003/unifi?url ver=Z39.88-

$2004 \& \mathrm{rft}$ val fimt $=$ info $\% 3 \mathrm{Aofi} \% 2 \mathrm{Ffmt} \% 3 \mathrm{Akev} \% 3 \mathrm{Amtx} \% 3 \mathrm{Ajournal} \& \mathrm{rft} . \mathrm{genre}=$ article \&rft.jtitle $=$ Journal $\% 20 \mathrm{of} \% 20 \mathrm{Mathematical} \% 20 \mathrm{Economics} \& \mathrm{rft}$.atitle=]

Caballé, J., and M. S. Santos (1993), On endogenous growth with physical and human capital, Journal of Political Economy 101, $1042-67$.

CrossRef(/resolve/reference/XREF?id=10.1086/261914), Web of Science $囚$ Times Cited: 108 (/resolve/reference/ISI?id=A1993MP30800004)

- Go here for SFX (http://192.167.125.34:9003/unifi?url ver=Z39.88-

2004\&rft val fimt=info $\% 3$ Aofi $\% 2 \mathrm{Ffmt} \% 3 \mathrm{Akev} \% 3 \mathrm{Amtx} \% 3$ Ajournal\&rft.genre=article\&rft.jtitle=Journal $\% 20$ of $\% 20 \mathrm{Political} \% 20 \mathrm{Economy} \& \mathrm{rft}$. atitle $=\mathrm{On} \% 20$

Carboni, O. A., and P. Russu (2013), Linear production, externalities and indeterminacy in a capital-resource growth model, Journal of Mathematical Economics 49, 422-8.

CrossRef (/resolve/reference/XREF?id=10.1016/j.jmateco.2013.04.002), Web of Science $($ (/resolve/reference/ISI?id=000324610000009)

- Go here for SFX (http://192.167.125.34:9003/unifi?url ver=Z39.882004\&rft_val_fimt=info $\% 3$ Aofi $\% 2 \mathrm{Ffmt} \% 3 \mathrm{Akev} \% 3 \mathrm{Amtx} \% 3$ Ajournal\&rft.genre=article\&rft.jtitle=Journal $\% 20 \mathrm{of} \% 20 \mathrm{Mathematical} \% 20 \mathrm{Economics} \& \mathrm{rft}$.atitle=]

Coury, T., and Y. Wen (2009), Global indeterminacy in locally determinate real business cycle models, International Journal of Economic Theory 5 , 49-60. Direct Link:

- Abstract (/doi/10.1111/j.1742-7363.2008.00102.x/abstract)

- Full Article (HTML) (/doi/10.1111/j.1742-7363.2008.00102.x/full)

- $\underline{\operatorname{PDF}(153 \mathrm{~K})(/ \mathrm{doi} / 10.1111 / \mathrm{j} .1742-7363.2008 .00102 . \mathrm{x} / \mathrm{epdf})}$

- $\operatorname{PDF}(153 \mathrm{~K})(/ \mathrm{doi} / 10.1111 / \mathrm{j} .1742-7363.2008 .00102 . \mathrm{x} / \mathrm{pdf})$

- $\underline{\text { References (/doi/10.1111/j.1742-7363.2008.00102.x/references) }}$

- Web of Science ${ }^{\circledR}$ Times Cited: 4 (/resolve/reference/ISI? id=000263342400004)

- Go here for SFX (http://192.167.125.34:9003/unifi?url ver=Z39.88- 
Dechert, W. D., and K. Nishimura (1983), A complete characterization of optimal growth paths in an aggregated model with a non-concave production function, Journal of Economic Theory 31, 332-54.

CrossRef(/resolve/reference/XREF?id=10.1016/0022-0531(83)90081-9), Web of Science $囚$ Times Cited: 142 (/resolve/reference/ISI?id=A1983RU41800009)

- Go here for SFX (http://192.167.125.34:9003/unifi?url ver=Z39.88-

2004\&rft val_fint=info $\% 3$ Aofi $\% 2 \mathrm{Ffmit} \% 3 \mathrm{Akev} \% 3 \mathrm{Amtx} \% 3 \mathrm{Ajournal} \& \mathrm{rft}$.genre=article\&rft.jtitle=Journal $\% 20 \mathrm{of} \% 20 \mathrm{Economic} \% 20 \mathrm{Theory} \& \mathrm{rft}$. atitle $=\mathrm{A} \% 20 \mathrm{c}$

Gori, L., and M. Sodini (2011), Nonlinear dynamics in an OLG growth model with young and old agents labour supply: The role of public health expenditure,

Computational Economics 38, 261-75.

CrossRef(/resolve/reference/XREF?id=10.1007/s10614-011-9283-x), Web of Science® Times Cited: 3 (/resolve/reference/ISI?id=000295991500005)

- Go here for SFX (http://192.167.125.34:9003/unif?url ver=Z39.88-

2004\&rft val fimt=info $\% 3$ Aofi $\% 2 \mathrm{Ffmit} \% 3 \mathrm{Akev} \% 3 \mathrm{Amtx} \% 3 \mathrm{Ajournal} \& \mathrm{rft}$.genre=article\&rft.jtitle=Computational $\% 20$ Economics \&rft. atitle=Nonlinear $\% 20 \mathrm{dyn}$

Gori, L., and M. Sodini (2014), Indeterminacy and nonlinear dynamics in an OLG growth model with endogenous labour supply and inherited tastes, Decisions in Economics and Finance 37, 159-79.

CrossRef(/resolve/reference/XREF?id=10.1007/s10203-013-0146-x)

- Go here for SFX (http://192.167.125.34:9003/unifi?url ver=Z39.88-

2004\&rft val_fimt=info $\% 3 \mathrm{Aofi} \% 2 \mathrm{Ffmit} \% 3 \mathrm{Akev} \% 3 \mathrm{Amtx} \% 3 \mathrm{Ajournal} \& \mathrm{rft}$ genre=article\&rft.jitle=Decisions $\% 20 \mathrm{in} \% 20 \mathrm{Economics} \% 20$ and $\% 20 \mathrm{Finance} \& \mathrm{rft}$.at

Guckenheimer, J., and P. Holmes (1997), Nonlinear Oscillations, Dynamical Systems and Bifurcations of Vector Fields, Berlin: Springer-Verlag.

- Go here for SFX (http://192.167.125.34:9003/uniff?url ver=Z39.88-

2004\&rft val fimt=info $\% 3 \mathrm{Aofi} \% 2 \mathrm{Ffmit} \% 3 \mathrm{Akev} \% 3 \mathrm{Amtx} \% 3 \mathrm{Ajournal} \& \mathrm{rft}$.genre=article\&rft.jtitle=Nonlinear $\% 20 \mathrm{Oscillations} \% 2 \mathrm{C} \% 20 \mathrm{Dynamical} \% 20 \mathrm{Systems}$

Kopell, N., and L. N. Howard (1975), Bifurcations and trajectories joining critical points, Advances in Mathematics 18, 306-58.

CrossRef(/resolve/reference/XREF?id=10.1016/0001-8708(75)90048-1), Web of Science ${ }^{\circledR}$ Times Cited: 82 (/resolve/reference/ISI?id=A1975BG38200005)

○ Go here for SFX (http:/192.167.125.34:9003/unifi?url ver=Z39.88-

2004\&rft val fimt=info $\% 3 \mathrm{Aofi} \% 2 \mathrm{Ffmit} \% 3 \mathrm{Akev} \% 3 \mathrm{Amtx} \% 3 \mathrm{Ajournal} \& \mathrm{rft}$.genre=article\&rft.jtitle=Advances $\% 20 \mathrm{in} \% 20 \mathrm{Mathematics} \& \mathrm{rft}$.atitle=Bifurcations $\%$.

Krugman, P. (1991), History versus expectations, Quarterly Journal of Economics 106, 651-67.

CrossRef $(/$ resolve/reference/XREF?id=10.2307/2937950), Web of Science $®$ Times Cited: 244 (/resolve/reference/ISI?id=A1991FK93200010)

- Go here for SFX (http:/192.167.125.34:9003/unifi?url ver=Z39.88-

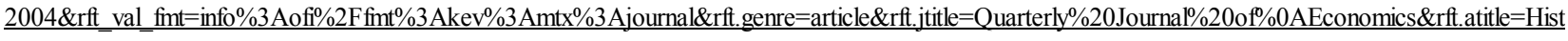

Matsuyama, K. (1991), Increasing returns, industrialization, and indeterminacy of equilibrium, Quarterly Journal of Economics 106, 617-50.

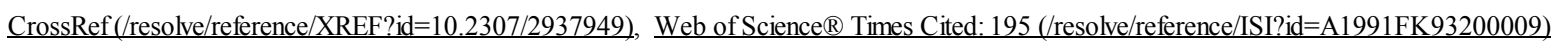

- Go here for SFX (http://192.167.125.34:9003/unif?url ver=Z39.882004\&rft val_fint=info $\% 3 \mathrm{Aofi} \% 2 \mathrm{Ffmit} \% 3 \mathrm{Akev} \% 3 \mathrm{Amtx} \% 3 \mathrm{Ajournal} \& \mathrm{rft}$.genre=article\&rft.jtitle=Quarterly $\% 20 \mathrm{Journal} \% 20 \mathrm{of} \% 20$ Economics\&rft.atitle=Incrs

Mattana, P. (2004), The Uzawa-Lucas Endogenous Growth Model, Aldershot: Ashgate.

- Go here for SFX (http://192.167.125.34:9003/uniff?url ver=Z39.882004\&rft val_fimt=info $\% 3$ Aofi $\% 2 \mathrm{Ffmit} \% 3 \mathrm{Akev} \% 3 \mathrm{Amtx} \% 3 \mathrm{Ajournal} \& \mathrm{rft}$.genre=article\&rft.jtitle=The $\% 20$ Uzawa $\% \mathrm{E} 2 \% 80 \% 93 \mathrm{Lucas} \% 20$ Endogenous $\% 20 \mathrm{C}$

Mattana, P., K. Nishimura, and T. Shigoka (2009), Homoclinic bifurcation and global indeterminacy of equilibrium in a two-sector endogenous growth model,

International Journal of Economic Theory 5, 25-47.

Direct Link:

- $\underline{\operatorname{Abstract}(/ \mathrm{doi} / 10.1111 / \mathrm{j} .1742-7363.2008 .00093 . \mathrm{x} / \mathrm{abstract})}$

- Full Article (HTML) (/doi/10.1111/j.1742-7363.2008.00093.x/full)

- $\underline{\operatorname{PDF}(378 \mathrm{~K})(/ \mathrm{doi} / 10.1111 / \mathrm{j} .1742-7363.2008 .00093 . \mathrm{x} / \mathrm{epdf})}$

- $\operatorname{PDF}(378 \mathrm{~K})(/ \mathrm{doi} / 10.1111 / \mathrm{j} .1742-7363.2008 .00093 . \mathrm{x} / \mathrm{pdf})$

- References (/doi/10.1111/j.1742-7363.2008.00093.x/references)

- Web of Science ${ }^{\circledR}$ Times Cited: 6 (/resolve/reference/ISI?id=000263342400003)

- Go here for SFX (http://192.167.125.34:9003/unifi?url ver=Z39.882004\&rft_val_fmt=info $\% 3 \mathrm{Aofi} \% 2 \mathrm{Ffmt} \% 3 \mathrm{Akev} \% 3 \mathrm{Amtx} \% 3 \mathrm{Ajournal} \& \mathrm{rft}$. genre=article\&rft.jtitle=International $\% 20 \mathrm{Journal} \% 20 \mathrm{of} \% 20 \mathrm{Economic} \% 20 \mathrm{Theory} \&$

Mattana, P., and B. Venturi (1999), Existence and stability of periodic solutions in the dynamics of endogenous growth, International Review of Economics and Business 46, 259-84.

- Go here for SFX (http://192.167.125.34:9003/unifi?url_ver=Z39.882004\&rft val fimt $=$ info $\% 3$ Aofi $\% 2 \mathrm{Ffmt} \% 3 \mathrm{Akev} \% 3 \mathrm{Amtx} \% 3 \mathrm{Ajournal} \& \mathrm{rft}$. genre $=$ article\&rft.jtitle $=$ International $\% 20 \mathrm{Review} \% 20 \mathrm{of} \% 20 \mathrm{Economics} \% 20 \mathrm{and} \% 2 \mathrm{O}$

Mino, K. (2001), Indeterminacy and endogenous growth with social constant returns, Journal of Economic Theory 97, $203-22$.

CrossRef(/resolve/reference/XREF?id=10.1006/jeth.2000.2693), Web of Science ${ }^{\circledR}$ Times Cited: 35 (/resolve/reference/ISI?id=000167925900010)

- Go here for SFX (http://192.167.125.34:9003/unifi?url ver=Z39.882004\&rft val fimt=info $\% 3$ Aofi $\% 2 \mathrm{Ffmt} \% 3 \mathrm{Akev} \% 3 \mathrm{Amtx} \% 3$ Ajournal\&rft.genre=article\&rft.jtitle $=$ Journal $\% 20$ of $\% 20$ Economic $\% 20 \mathrm{Theory} \& \mathrm{rft}$.atitle $=$ Indeterr

Mino, K. (2004), Human capital formation and patterns of growth with multiple equilibria, M. Boldrin, B. Chen, and P. Wang, eds, Human Capital, Trade, and Public Policy in Rapidly Growing Economies: From Theory to Empirics, Academia Studies in Asian Economies, 42-64, Cheltenham: Edward Elgar.

Web of Science $\AA$ Times Cited: 4 (/resolve/reference/ISI?id=000231181200003)

- Go here for SFX (http://192.167.125.34:9003/unifi?url ver=Z39.882004\&rft val fimt=info $\% 3$ Aofi $\% 2 \mathrm{Ffmt} \% 3 \mathrm{Akev} \% 3 \mathrm{Amtx} \% 3 \mathrm{Abook} \& \mathrm{rft}$.genre=bookitem\&rft.btitle=Human $\% 20 \mathrm{Capital} \% 2 \mathrm{C} \% 20 \mathrm{Trade} \% 2 \mathrm{C} \% 20 \mathrm{and} \% 20 \mathrm{Pul}$

Mino, K., K. Nishimura, K. Shimomura, and P. Wang (2008), Equilibrium dynamics in discrete-time endogenous growth models with social constant returns, Economic Theory 34, 1-23.

CrossRef(/resolve/reference/XREF?id=10.1007/s00199-007-0211-1), Web of Science® Times Cited: 4 (/resolve/reference/ISI?id=000250116500001) 
- Go here for SFX (http://192.167.125.34:9003/unifi?url ver=Z39.88-

2004\&rft_val_fimt=info $\% 3 \mathrm{Aofi} \% 2 \mathrm{Ffmt} \% 3 \mathrm{Akev} \% 3 \mathrm{Amtx} \% 3 \mathrm{Ajournal} \& \mathrm{rft}$. genre=article\&rft.jtitle=Economic $\% 20 \mathrm{Theory} \& \mathrm{rft}$.atitle=Equilibrium $\% 20 \mathrm{dynamics} \%$

Mulligan, C. B., and X. Sala-i-Martin (1993), Transitional dynamics in two-sector models of endogenous growth, Quarterly Journal of Economics 103, 739-73.

CrossRef(/resolve/reference/XREF?id=10.2307/2118407), Web of Science ${ }^{\circledR}$ Times Cited: 125 (/resolve/reference/ISI?id=A1993LV00700008)

- Go here for SFX (http://192.167.125.34:9003/unifi?url ver=Z39.88-

2004\&rft val_fimt=info $\% 3$ Aofi $\% 2 \mathrm{Ffmt} \% 3 \mathrm{Akev} \% 3 \mathrm{Amtx} \% 3$ Ajournal\&rft.genre=article\&rft.jitle=Quarterly $\% 20 \mathrm{Journal} \% 20 \mathrm{of} \% 20 \mathrm{Economics} \& \mathrm{rft}$.atitle=Tran

Nishimura, K., and T. Shigoka (2006), Sunspots and Hopf bifurcations in continuous time endogenous growth models, International Journal of Economic Theory 2, 199-216.

Direct Link:

- $\underline{\text { Abstract (/doi/10.1111/j.1742-7363.2006.0033.x/abstract) }}$

- $\underline{\operatorname{PDF}(200 \mathrm{~K})(/ \mathrm{doi} / 10.1111 / \mathrm{j} .1742-7363.2006 .0033 . x / \mathrm{epdf})}$

- $\underline{\operatorname{PDF}(200 \mathrm{~K})(/ \mathrm{doi} / 10.1111 / \mathrm{j} .1742-7363.2006 .0033 . \mathrm{x} / \mathrm{pdf})}$

- $\underline{\text { References (/doi/10.1111/j.1742-7363.2006.0033.x/references) }}$

- Go here for SFX (http://192.167.125.34:9003/unif?url ver=Z39.882004\&rft val fimt=info\%3Aofi\%2Ffmt $\% 3 \mathrm{Akev} \% 3 \mathrm{Amtx} \% 3 \mathrm{Ajournal} \& \mathrm{rft}$.genre=article\&rft.jitile=International\%20Journal\%20of\%20Economic\%20Theory\&

Raurich-Puigdevall, X. (2000), Global indeterminacy in an endogenous-growth model with public capital, Journal of Economics 71, $255-80$.

CrossRef(/resolve/reference/XREF?id=10.1007/BF01228743), Web of Science $®$ Times Cited: 7 (/resolve/reference/ISI?id=000088010500002)

- Go here for SFX (http:/192.167.125.34:9003/unifi?url ver=Z39.882004\&rft val fimt=info $\% 3 \mathrm{Aofi} \% 2 \mathrm{Ffmit} \% 3 \mathrm{Akev} \% 3 \mathrm{Amtx} \% 3 \mathrm{Ajournal} \& \mathrm{rft}$.genre=article\&rft.jtitle=Journal $\% 20 \mathrm{of} \% 20$ Economics\&rft.atitle=Global $\% 20$ indetern

Sethi, S. P. (1997), Nearest feasible paths in optimal control problems: Theory, examples and counterexamples, Journal of Optimization Theory and Applications 23, 563-79.

CrossRef(/resolve/reference/XREF?id=10.1007/BF00933297), Web of Science $§$ Times Cited: 29 (/resolve/reference/ISI?id=A1977EW49000005)

- Go here for SFX (http:/192.167.125.34:9003/unifi?url ver=Z39.882004\&rft val fmt=info $\% 3$ Aofi $\% 2 \mathrm{Ffmt} \% 3 \mathrm{Akev} \% 3 \mathrm{Amtx} \% 3$ Ajournal\&rft.genre=article\&rft.jtitle=Journal $\% 20 \mathrm{of} \% 20 \mathrm{Optimization} \% 20 \mathrm{Theory} \% 20 \mathrm{and} \% 20 \mathrm{Ap}$

Sijbrand, J. (1985), Properties of center manifolds, Transactions of the American Mathematical Society 289, 431-69.

CrossRef(/resolve/reference/XREF?id=10.1090/S0002-9947-1985-0783998-8)

- Go here for SFX (http://192.167.125.34:9003/unifi?url ver=Z39.88-

2004\&rft val fimt=info $\% 3$ Aofi $\% 2 \mathrm{Ffmt} \% 3 \mathrm{Akev} \% 3 \mathrm{Amtx} \% 3 \mathrm{Ajournal} \& \mathrm{rft}$.genre $=$ article\&rft.jitle $=$ Transactions $\% 20 \mathrm{of} \% 20$ the $\% 0 \mathrm{AAmerican} \% 20 \mathrm{Mathematic} \varepsilon$

Skiba, A. (1978), Optimal growth with a convex-concave production function, Econometrica 46, 527-40.

CrossRef(/resolve/reference/XREF?id=10.2307/1914229), Web of Science ${ }^{\circledR}$ Times Cited: 156 (/resolve/reference/ISI?id=A1978FJ62200003)

- Go here for SFX (http://192.167.125.34:9003/uniff?url ver=Z39.88-

2004\&rft val_fimt=info $\% 3$ Aofi $\% 2 \mathrm{Ffimt} \% 3 \mathrm{Akev} \% 3 \mathrm{Amtx} \% 3 \mathrm{Ajournal} \& \mathrm{rft}$.genre=article\&rft.jtitle=Econometrica\&rft.atitle=Optimal $\% 20$ growth $\% 20$ with $\% 20 \mathrm{a}$

Slobodyan, S. (2007), Indeterminacy and stability in a modified Romer model, Journal of Macroeconomics 29, 169-77.

CrossRef(/resolve/reference/XREF?id=10.1016/j.jmacro.2005.08.001), Web of Science ${ }^{\circledR}$ Times Cited: 4 (/resolve/reference/ISI?id=000245609400010)

- Go here for SFX (http:/192.167.125.34:9003/unifiurl ver=Z39.88-

2004\&rft val fimt=info $\% 3 \mathrm{Aofi} \% 2 \mathrm{Ffimt} \% 3 \mathrm{Akev} \% 3 \mathrm{Amtx} \% 3 \mathrm{Ajournal} \& \mathrm{rft}$.genre=article\&rft.jtitle=Journal $\% 20 \mathrm{of} \% 20 \mathrm{Macroeconomics} \& \mathrm{rft}$.atitle=Indeterminar

Zhou, Y., C. Wang, and D. Blackmore (2005), The uniqueness of limit cycles for Liénard systems, Journal of Mathematical Analysis and Applications 304, 473-89.

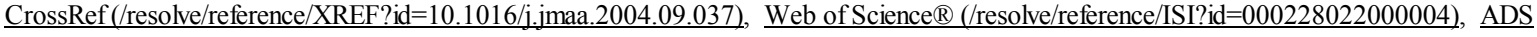

(/resolve/reference/ADS?id=2005JMAA..304..473Z)

- Go here for SFX (http://192.167.125.34:9003/unifi?url ver=Z39.88-

2004\&rft_val_fint=info $\% 3$ Aofi $\% 2 \mathrm{Ffmt} \% 3 \mathrm{Akev} \% 3 \mathrm{Amtx} \% 3$ Ajournal\&rft.genre=article\&rft.jtitle=Journal $\% 20$ of $\% 20 \mathrm{Mathematical} \% 20 \mathrm{Analysis} \% 20 \mathrm{and} \% 20 \mathrm{~F}$

Enhanced Article (HTML) (http:/onlinelibrary.wiley.com/enhanced/doi/10.1111/ijet.12042) Get PDF (825K) (/doi/10.1111/ijet.12042/epdf)Get PDF (825K)

$\underline{\text { (/doi/10.1111/ijet.12042/pdf) }}$

- Go here for SFX (http:/192.167.125.34:9003/unifi?url ver=Z39.88-

2004\&rft val fimt=info $\% 3$ Aofi $\% 2 \mathrm{Ffint} \% 3 \mathrm{Akev} \% 3 \mathrm{Amtx} \% 3 \mathrm{Ajournal} \& \mathrm{rft}$. genre=article\&rft.jtitle=International $\% 20 \mathrm{Journal} \% 20 \mathrm{of} \% 20 \mathrm{Economic} \% 20 \mathrm{Theory} \& \mathrm{rft}$. stitle=Int $\% 20 \mathrm{Jnl} \% 20$ 12-01\&rft. issn $=1742-7355 \&$ rft.eissn $=1742-7363 \& \mathrm{rfr}$ id $=$ info $\% 3$ Asid $\% 2$ Fwiley.com $\% 3$ AOnlineLibrary)

\section{More content like this}

Find more content:

- $\underline{\text { like this article (/advanced/search/results?articleDoi=10.1111/ijet.12042\&scope=allContent\&start=1\&resultsPerPage=20) }}$

Find more content written by:

- Angelo Antoci (/advanced/search/results?searchRowCriteria[0].queryString="Angelo Antoci"\&searchRowCriteria[0].fieldName=author\&start=1\&resultsPerPage=20)

- Marcello Galeotti (/advanced/search/results?searchRowCriteria[0].queryString="Marcello Galeotti"\&searchRowCriteria[0].fieldName=author\&start=1\&resultsPerPage=20)

- Paolo Russu (/advanced/search/results?searchRowCriteria[0].queryString="Paolo Russu"\&searchRowCriteria[0].fieldName=author\&start=1\&resultsPerPage=20)

- All Authors (/advanced/search/results?searchRowCriteria[0].queryString="Angelo Antoci" "Marcello Galeotti" "Paolo Russu"\&searchRowCriteria[0].fieldName=author\&start=1\&resultsPerPage=20) 